Gerardo J. Cueto Alonso

Gerardo J. Cueto Alonso

Doctor en Geografia Profesor Contratado Doctor del Departamento de Geografia, Urbanismo y Ordenación del Territorio de la Universidad de Cantabria

\title{
La huella del pasado industrial agroalimentario en el paisaje de Cantabria
}

Palabras clave: agroalimentario, Cantabria, patrimonio industrial, harineras, lácteo, conserveras, arqueología industrial.

Por la variedad y fragmentación del sector agroalimentario en Cantabria éste se presenta como un sector complejo. Sus establecimientos son además en general de poca dimensión con algunas excepciones de fábricas modernas de tamaño mediano. Es preciso un laborioso trabajo de campo para obtener un registro mínimamente completo. En muchas ocasiones las instalaciones están ya en desuso prolongado, han desaparecido o han sufrido importantes transformaciones. Fruto del mencionado trabajo, el articulo recoge ordenadamente los principales elementos patrimoniales de los sectores harinero, lácteo, conservero, tabaquero, asi como aspectos complementarios como el de los mataderos y mercados. En ellos, aspectos como la orografía o la situación costera han constituido importantes determinantes.

\section{Introducción}

Ala hora de analizar la huella de la Aindustrialización agroalimentaria en el paisaje de Cantabria se deben tener en cuenta algunos aspectos que han definido la evolución del sector desde finales del siglo XVIII.

En primer lugar la escasa dimensión de los establecimientos industriales. Salvo excepciones, alguna desde luego extraordinaria como la fábrica de tabacos, nos encontramos con pequeños establecimientos muchas veces de carácter familiar y excepcionalmente con empresas de corte capitalista que instalaron modernas fábricas de mediano tamaño. Así, resulta comprensible que la huella de esta industrialización no resulte tan visible en el territorio como la de otros sectores como el minero, el siderometalúrgico o el químico, que no sólo fueron capaces de generar factorias propias de una gran empresa, sino que también formaron en su entorno un dependiente entramado industrial, aparte de sus propios espacios sociales.

El sector agroalimentario es un sector complejo, especialmente cuando se pretende encontrar huellas de su actividad. Algunas actividades llevan décadas abandonadas, como las harineras o cerveceras, mientras otras que se mantienen pujantes, como el conservero, han sufrido el obligado desalojo de sus originales centros de trabajo para ocupar modernos polígonos industriales. Por su parte, el sector lácteo dejó hace décadas de ser el abastecedor nacional de leche fresca y transformados lácteos hasta el punto de carecer de una industria transformadora de capital regio- nal en la actualidad, si bien todavia mantiene varias fábricas originales en actividad.

Esta diversidad de trayectorias implica necesariamente que el trabajo de campo para descubrir su impronta en el paisaje cántabro deba ser al menos trabajosa. Tenemos que enfrentarnos a fábricas que continúan en actividad, lo que implica que los edificios originales han podido sufrir una profunda transformación hasta hacerlos irreconocibles, lo que es inherente a la propia naturaleza de la industria. En otros casos, los viejos edificios en desuso se han remozado y adaptado a nuevas actividades, si éstas son productivas desde el punto de vista industrial pueden conllevar la pérdida de algunos elementos originales, aunque no se trataría más que de un proceso de adaptación funcional. En esta categoria podríamos incluir, con muchos reparos, los muy escasos ejemplos de reutilización patrimonial con fines turísticoculturales. Finalmente, por desgracia, un numeroso grupo de elementos se encontraría conformado por establecimientos industriales desaparecidos. Las causas de la demolición de un edificio industrial son muy variadas y no podrian encasillarse en una única clasificación: intereses urbanísticos por su proximidad o inclusión dentro de la trama urbana, sobre todo en municipios turísticos; deterioro ambiental que aconseja su derribo; ampliación de las infraestructuras de transporte...

\section{El sector harinero}

La industria harinera en Cantabria recibió el impulso necesario para su desarrollo con la apertura del Camino Real de Reino- 
sa en 1753 y la habilitación del puerto de Santander para el tráfico colonial en 1778. En Campoo y el valle del Besaya, por su ubicación idónea para la llegada de los trigos castellanos y la salida de las harinas hacia el puerto santanderino, se comenzaron a instalar varias harineras a finales del siglo XVIII (Ansola y Sierra 2007: 154; Palacio 1960: 150). Tras una época de esplendor, los cambios políticos, comerciales, etc. que se empezaron a producir en la segunda mitad del siglo XIX condujeron a la decadencia del sector que se agudizó con la pérdida del mercado colonial en 1898. Así, se fue asistiendo a la desaparición continuada de fábricas harineras, en ocasiones reconvertidas en fábricas de luz, hasta que hace un par de décadas cerrara la última harinera de Cantabria (Ansola y Sierra 2007: 157).

Cuando hablamos de una fábrica harinera nos referimos a un complejo que no se limita a moler el grano como lo hicieron en el pasado los molinos, sino que estamos hablando de un aprovechamiento hidráulico que no sólo sirve para moler, sino que también incluye espacios de transformación, almacenaje, clasificación, etc. Todavía hoy se puede recorrer los valles del Besaya y del Ebro, reconociendo y admirando algunos de sus fabulosos monumentos industriales.

Izquierda. Figura 1. Fábrica de harinas. Salces. Colección del autor, 2016.

Derecha. Figura 2. Fábrica de harinas La Flor del Ebro. Nestares. Colección del autor, 2016.
Las aguas del río Ebro sirvieron para mover la maquinaria de numerosas fábricas harineras, aunque de algunas tan sólo se conserva su memoria documental y gráfica otras han resistido el paso del tiempo adaptadas a nuevos usos (Ruiz Gómez 2011: 14-19). La primera que topamos siguiendo el cauce del río es la fábrica de Salces o de las Pisas (figura 1), una impo- nente fábrica de cuatro pisos en la que actualmente se aprovecha la vieja calcera como piscifactoría y el edificio fabril para uso residencial y horno de pan.

Aguas abajo, ya en el pueblo de Nestares, encontramos la fábrica de Ciella, un pequeño complejo con varias edificaciones originales muy transformadas, ya que también fue fábrica de luz, la primera en llevar la electricidad a Reinosa, y fábrica de madera, aparte del uso residencial actual de algunas de ellas. Del edificio fabril, en proceso de reforma desde hace tiempo, no se conserva su cubierta, pero sí una chimenea de ladrillo que delata un cambio energético cuando dejó de utilizar la fuerza hidráulica.

En Nestares también podemos encontrar otros dos establecimientos vinculados a la familia García de los Ríos: el molino de Corbilla y la impresionante fábrica La Flor del Ebro (figura 2), que conserva en perfecto estado su equipamiento hidráulico y el edificio fabril gracias a su restauración como establecimiento de hostelería.

De las varias fábricas que hubo en Reinosa sólo quedan solares abandonados excepto la fábrica de la familia Obeso, construida sobre el viejo molino de San Esteban (figura 3). El edificio fabril y los auxiliares han sido reformados para acoger las salas del juzgado de primera instancia de Reinosa. Gracias a un muro cortina se puede observar la organización de la fábrica en tres pisos.

El gran río harinero de Cantabria fue el Besaya, cuyas aguas eran captadas casi en su nacimiento para mover la primera de las fábricas, la de Cañeda, conocida como
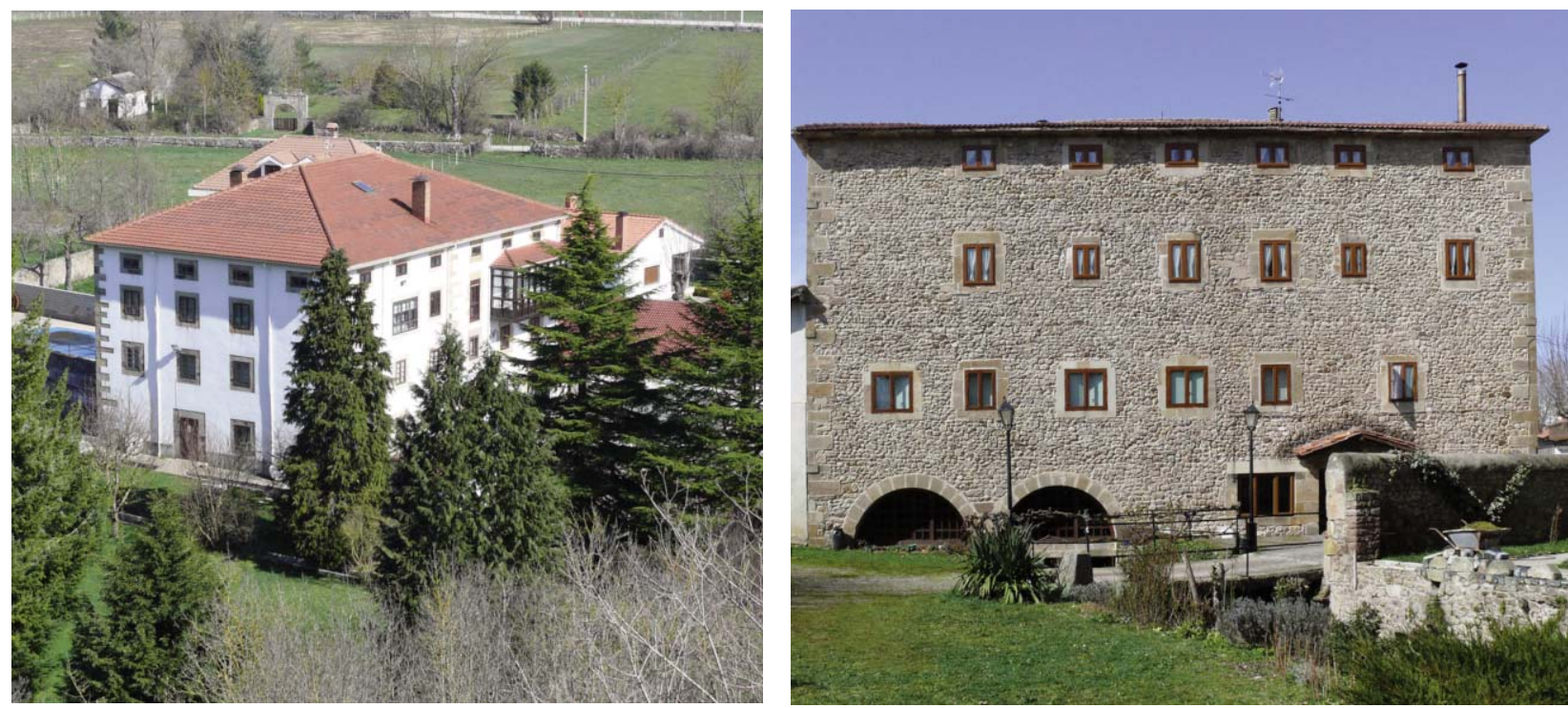

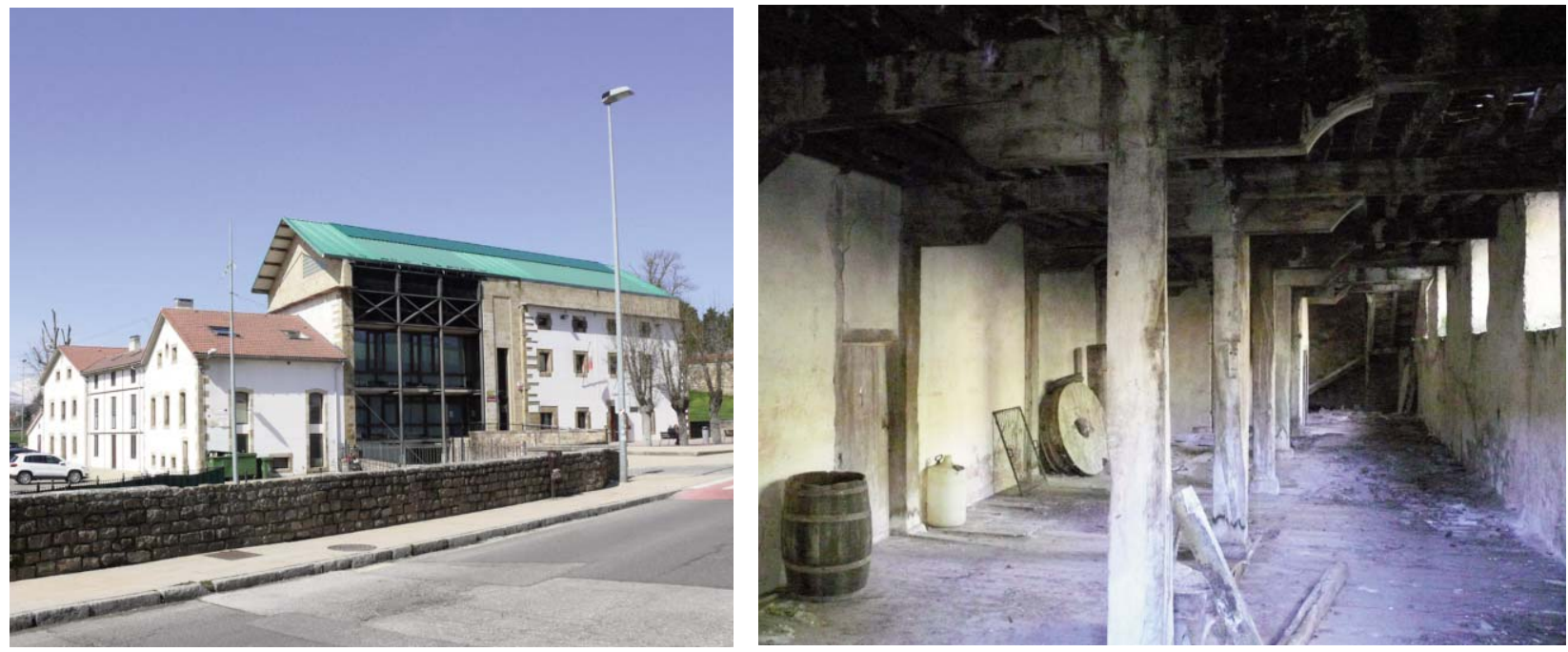

Izquierda. Figura 3. Fábrica de harinas de los Obeso. Reinosa. Colección del autor, 2016.

Derecha. Figura 4. Interior de la fábrica de harinas. Lantueno. Colección del autor, 2015.

Figura 5. Fábrica de harinas de la Venta Vieja. Santiurde de Reinosa. Colección del autor, 2012.

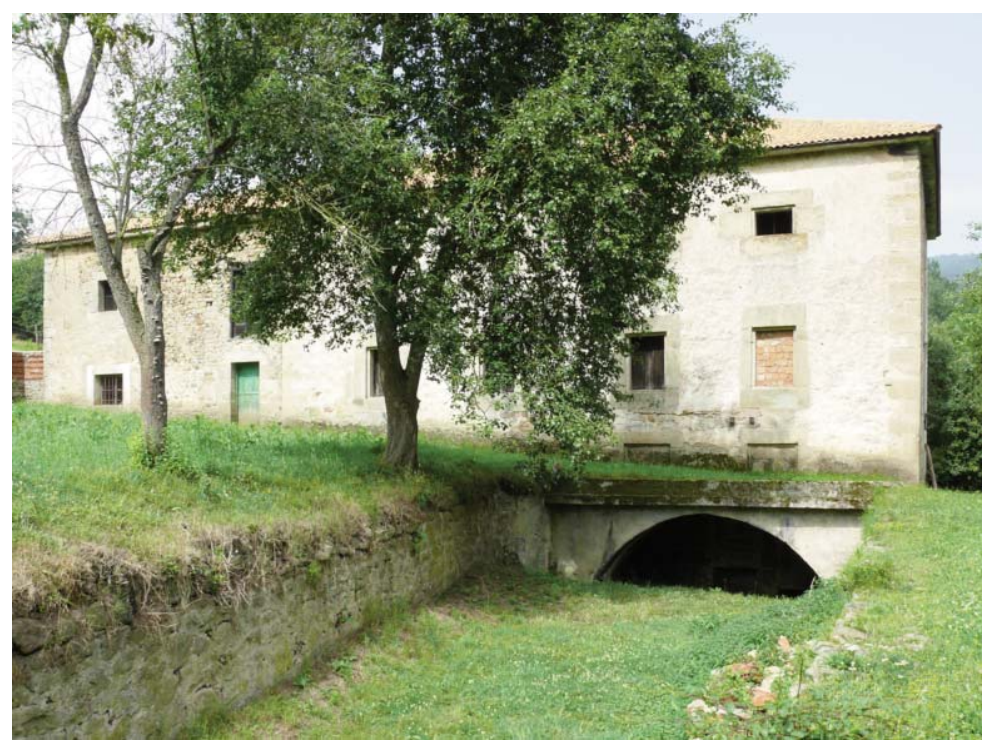

La Esperanza, que en los últimos años mantuvo su actividad como fábrica de yeso. El conjunto se encuentra muy arruinado: la obra hidráulica cegada y el edificio fabril sin cubierta con dos paramentos prácticamente colapsados.

En el municipio de Santiurde de Reinosa el Besaya proporcionaba energía a varias harineras. La primera de ellas es la conocida como fábrica de Lantueno (figura 4), probablemente la harinera más antigua de España, de la que se tienen noticias desde 1778 (Ansola y Sierra 2007: 177-180). Como la fábrica de Cañeda en sus últimos años de vida activa fue reconvertida en yesera. La obra hidráulica, tanto su caz como su socaz, en encuentran en buen estado, aunque lógicamente en la actualidad no circula agua por ellos. El edificio de planta cuadrada y dos pisos más desván se encuentra en buen estado, gracias en gran parte a la reciente reparación de su cubierta por su actual propietario. Precisa- mente éste ha presentado un proyecto para la recuperación de la fábrica como balneario, ya que se le ha concedido un aprovechamiento de aguas termales a un centenar de metros de la fábrica.

La fábrica de la Venta Vieja (figura 5) fue construida en la segunda mitad del siglo XIX, si bien su aspecto actual se debe a su reconstrucción tras un incendio en 1889 (Ansola y Sierra 2007: 180-181). Su planta rectangular con dos alturas más desván sobre la cámara de agua conserva muy bien su estructura, así como la obra hidráulica actualmente cegada.

La fábrica de Uzquiano o la Ferrería se encuentra totalmente irreconocible debido a su reconstrucción para acoger un establecimiento de explotación forestal, no obstante su obra hidráulica se intuye con más claridad.

La última fábrica del pueblo era conocida como La Dominica, de factura similar a otras del valle con dos plantas y desván albergó hasta hace poco tiempo un establecimiento de hostelería que desvirtuó en cierta medida el edificio original.

El siguiente municipio que atraviesa el río Besaya es Pesquera y como parece lógico también dio servicio a varias harineras. De las fábricas del Solar y El Gorgollón, la más importante a mediados del siglo $\mathrm{XX}$, apenas quedan restos; en el primer caso por la profunda remodelación realizada y en el segundo por su casi completa demolición con motivo de las obras de ensanchamiento de la carretera a finales de los años setenta.

La que se encuentra en mejor estado de conservación es La Montañesa, que resulta un interesante ejemplo de reutilización 

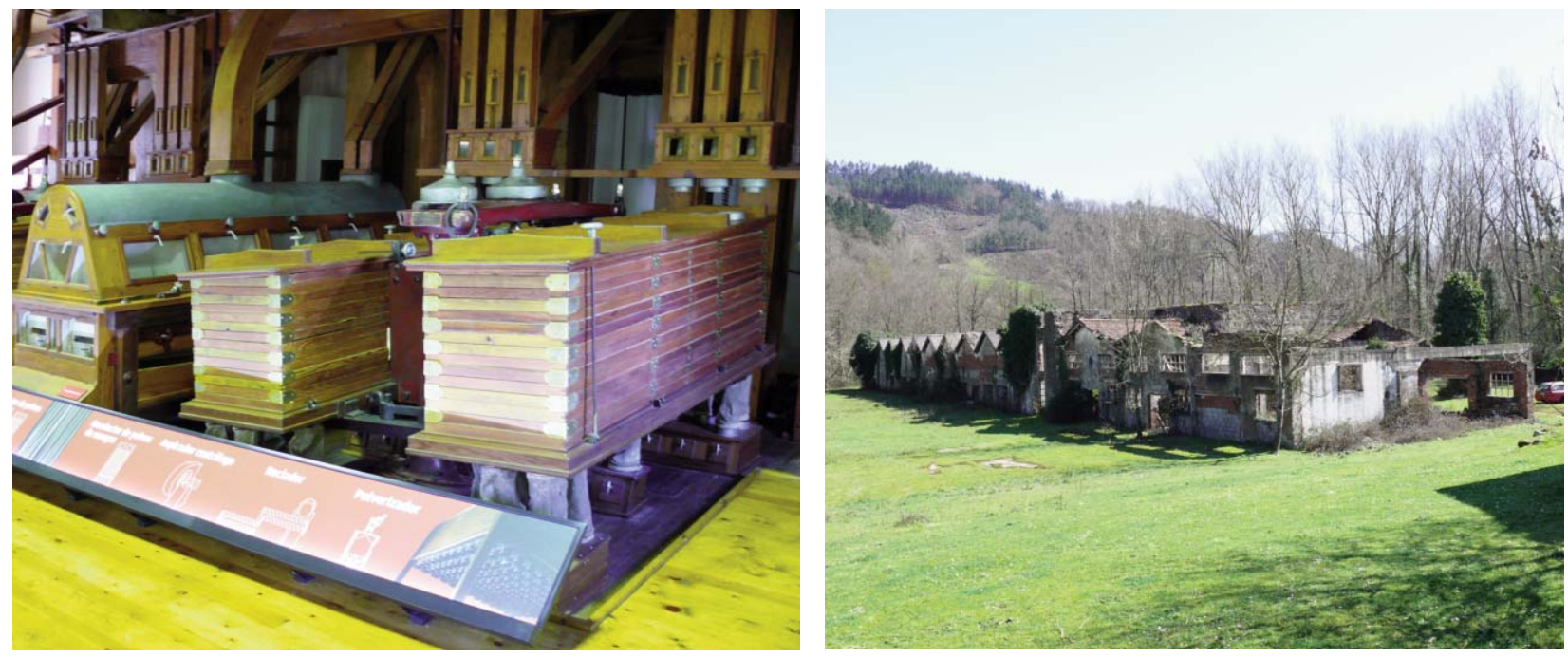

Izquierda. Figura 6. Interior de la fábrica de harinas La

Montañesa, actual Centro de Interpretación $\mathrm{El}$ Camino de las Harinas. Pesquera. Colección del autor, 2010.

Derecha. Figura 7. Fábrica de harinas La Cobrera. Santa Cruz de Iguña. Colección del autor, 2016. cultural del patrimonio industrial, ya que en la actualidad alberga el centro de interpretación El Camino de las Harinas que permite al visitante conocer la interesante historia caminera y harinera del valle del Besaya (figura 6). Se trata de una de las últimas harineras levantadas junto al río, por cuanto su construcción nos lleva a los años veinte del siglo pasado sobre la obra hidráulica de un antiguo molino (Ansola y Sierra 2007: 204-232).

En Bárcena de Pie de Concha se estableció a finales del siglo XVIII una harinera que estuvo activa hasta finales del siglo siguiente. En 1904 el edificio fue reutilizado como oficinas, laboratorio y taller de reparaciones de una fábrica de sosa; en la actualidad y probablemente desde el cierre de esta fábrica tiene uso residencial.

Una vez en el municipio de Molledo, el Besaya vuelve a ser captado para mover una fábrica en Portolín, que fue adaptada a principios del siglo XX para formar parte del conjunto fabril de Hilaturas de Portolín que se mantuvo en actividad prácticamente un siglo. De conservarse algún resto de la vieja harinera, aparte de la obra hidráulica, se encontraría disimulado entre otras instalaciones de la fábrica textil (Ansola y Sierra 2007: 188-189).

En Santa Cruz de Iguña, en el mismo municipio, nos encontramos con un interesante conjunto conocido por el nombre de La Cobrera (figura 7), si bien su uso industrial estuvo vinculado a las harinas desde mediados del siglo XIX y a las maderas en sus últimos años (Ansola y Sierra 2007: 189-191). Destaca en primer lugar la gran obra hidráulica con un azud oblicuo al lecho del río que da paso por medio de compuertas bien conservadas al caz que conducía el agua hasta la fábrica. El espacio fabril revela tres fases constructivas, siendo la más antigua en piedra la correspondiente a la harinera con planta en L, a ambos lados se encuentran las ampliaciones para la serrería y la fábrica de muebles. Junto a esta nave se levanta una chimenea troncopiramidal de ladrillo que denota la utilización en algún momento de otras fuentes de energía aparte de la hidráulica.

Sin dejar descansar al Besaya, unos metros más adelante un azud oblicuo vuelve a desviar el agua a La Inesuca (figura 8), la última harinera del municipio que data de finales del siglo XVIII (Ansola y Sierra 2007: 191-193). La obra hidráulica se conserva en perfecto estado ya que alimenta actualmente a una pequeña central eléctrica. Por el contrario, el edificio fabril se encuentra muy deteriorado, con la cubierta totalmente arruinada, no así sus gruesos muros que muestran la extraordinaria factura de la fábrica. El conjunto fabril se completaba con una hilera de viviendas para obreros y la villa del último propietario que continúan manteniendo su uso residencial.

Aguas abajo, ya en el municipio de Arenas de Iguña, un nuevo azud oblicuo desviaba las aguas del Besaya hacia la harinera conocida como la fábrica de La Herrán (figura 9), que se encontraba activa a comienzos del siglo XIX y que en sus últimos años estuvo destinada a la fabricación de piensos (Ansola y Sierra 2007: 193195). La obra hidráulica, empleada aguas arriba para una pequeña central eléctrica, cuenta con una calcera con sillares de bella factura. La fábrica era de cuatro pisos con al menos dos fases constructivas. 


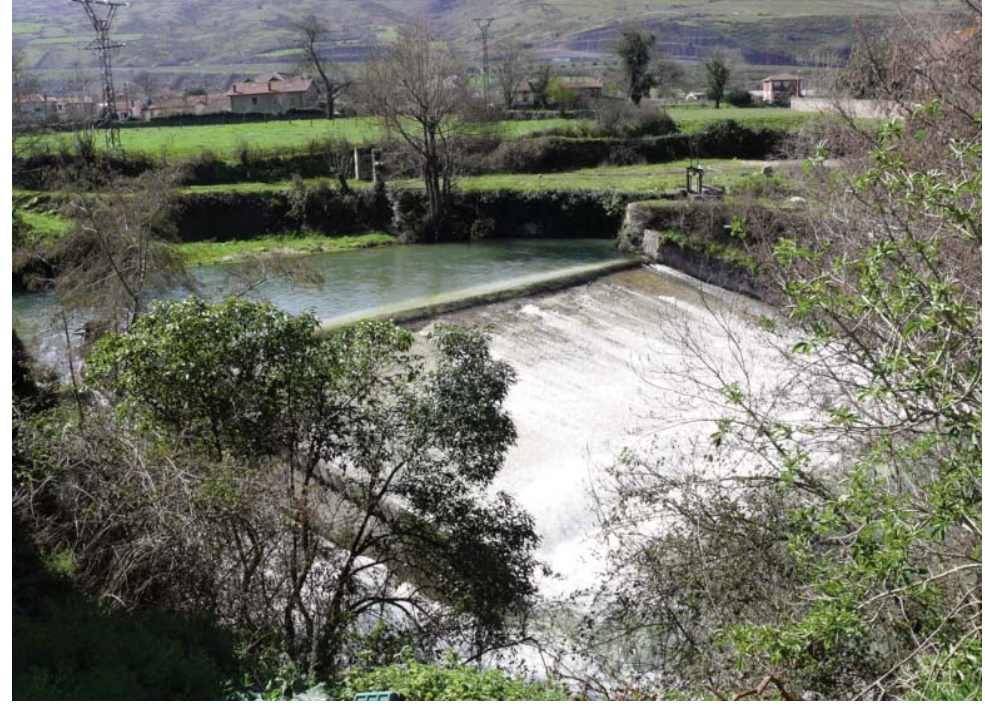

Figura 8. Azud para la fábrica de harinas La Inesuca. Santa Cruz de Iguña. Colección del autor, 2016.

Figura 9. Fábrica de harinas La Herrán. Arenas de Iguña. Colección del autor, 2016.

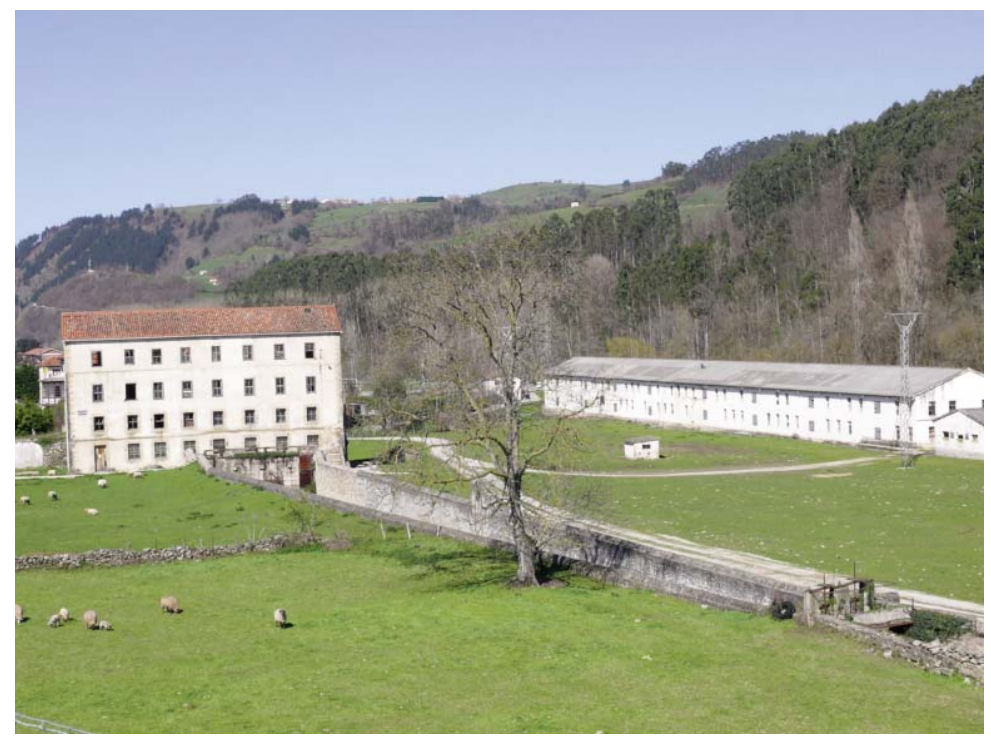

encuentra muy transformado con la inclusión, por ejemplo, de una pequeña central eléctrica. El edificio de la harinera de cuatro plantas incluye una pasarela para comunica la fábrica con el ferrocarril.

Una vez superada una pequeña hoz, el río Besaya busca su unión en Torrelavega con el río Saja no sin antes aportar la energía a otras fábricas. La primera de ellas al cabo de la hoz, una de las más antiguas del valle, de la que apenas quedan testimonios físicos más allá de algún detalle de su obra hidráulica.

De las varias harineras que hubo en el municipio de Torrelavega se conservan pocos restos. En Torres en la margen derecha del río encontramos un edificio de una planta y desván sobre la cámara de agua, cuya obra hidráulica se encuentra totalmente sellada. Las sucesivas reformas y adiciones al edificio original dificultan se reconocimiento como harinera.

En Barreda se encontraba la última harinera del río, tanto física como temporalmente hablando, que en sus últimos años funcionó bajo la razón social Harinor S. A. y fue derribada hace un par de años. A lo largo de su historia productiva fue fábrica de chocolate, conocida como La Constancia, molino de maíz y harinera (Cueto 2010: 379). El aprovechamiento hidráulico se conserva en muy buen estado, dado que Solvay lo utiliza para su fábrica de Barreda gracias a una presa que posee aguas abajo. Esta empresa fue la responsable de la oclusión de la presa del canal para permitir una mayor afluencia de agua a la suya propia.

\section{La fabricación de derivados lácteos}

La evolución de la industria láctea en Cantabria a lo largo del siglo XIX no hacía presagiar en absoluto el desarrollo que alcanzaría el siglo siguiente, por cuanto la transformación láctea se limitaba a pequeñas elaboraciones artesanales en los valles de Pas y Campoo, excepto la fábrica instalada por Claudio Napoleón Boffard en Reinosa, considerada como la primera que elaboró en España quesos de tipo extranjero. La escasez de leche era el principal impedimento, ya que aunque la cabaña era numerosa, la leche se destinaba a las crias, tanto si se destinaban a carne como si llegaban a ser vacas lecheras (De la Puente 1992: 169). El punto de inflexión fue la instalación en 1905 de Nestlé en La Penilla de Cayón para la fabricación de harina lacteada (Sierra y Corbera 2007). Esta empresa suiza transformó el paisaje rural cántabro que se tapizó de prados, 


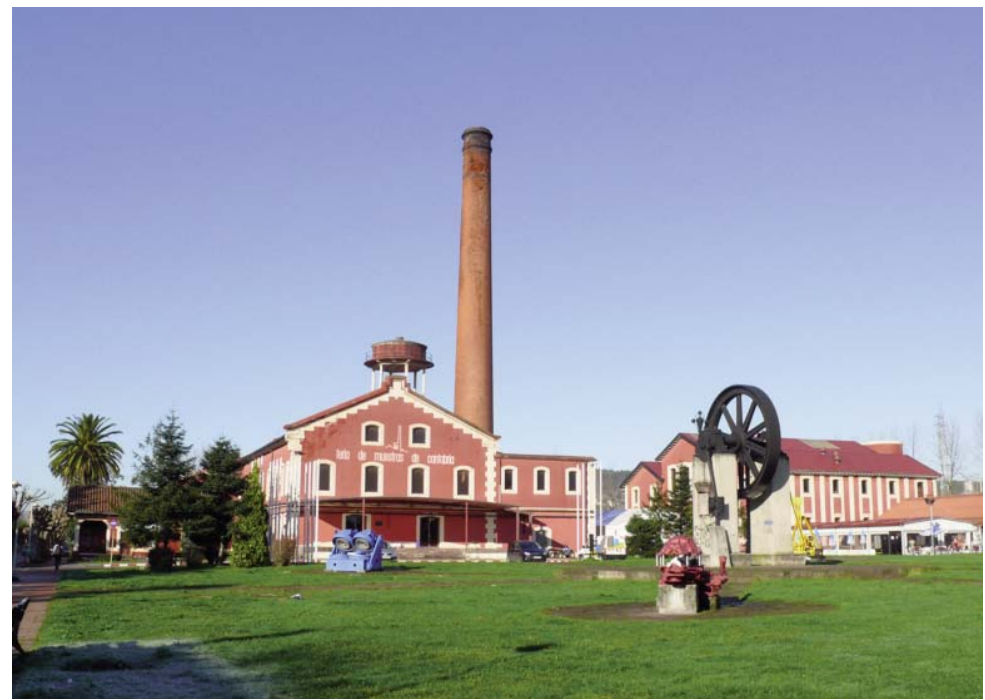

Figura 10. La Lechera Montañesa. Torrelavega. Colección del autor, 2008. industria láctea. En 1899 se construyó el edificio original para albergar las instalaciones de la Azucarera Montañesa (figura 10), que se mantuvo en activo hasta 1914. Tras años de abandono, en 1927 fueron reutilizados por La Lechera Montañesa, que absorbida por Nestlé cerró la fábrica en 1941 trasladando la producción de Queserias Reunidas a sus naves al año siguiente (Cueto 2011). Una vez que la quesera cesó la actividad los antiguos edificios de la azucarera permanecieron ociosos hasta que en los años ochenta se proyectó su reutilización. En un primer momento el Ayuntamiento de Torrelavega propuso su reacondicionamiento como museo industrial de la ciudad, que no fructificó pese a que ya se había obtenido maquinaria antigua de fábricas de la comarca que en la actualidad está expuesta en el exterior del edificio. Finalmente llegaría a buen puerto la ubicación en este espacio de la Feria de Muestras de Cantabria. Naturalmente para este nuevo uso los edificios tuvieron que ser acondicionados interiormente, pero su aspecto exterior apenas fue modificado, constituyendo en la actualidad uno de los mejores ejemplos de arquitectura industrial del siglo XIX en Cantabria. De hecho, ni siquiera durante su vida productiva sus sucesivos inquilinos realizaron cambios sustanciales en su aspecto original, salvo alguna modificación volumétrica en alguna nave o la adición de alguna nueva construcción. El conjunto construido enteramente en ladrillo continúa presidido por la gran chimenea de planta circular erigida en tiempos de la azucarera, flanqueada por el depósito de agua de la época de La Lechera Montañesa.

El establecimiento industrial de Nestlé en La Penilla de Cayón construido en 1905 ha ido ganando extensión y complejidad a lo largo de sus más de cien años de historia. Se requeriría un estudio minucioso para determinar la evolución de las instalaciones; no obstante, cabe suponer que algunas de las más antiguas se encuentren actualmente muy reformadas en el interior del conjunto fabril. El azud original en el río Pisueña y su caz, construidos simultáneamente a la fábrica, continúan en funcionamiento (figura 11). El barrio residencial situado al Norte de la fábrica fue demolido en los últimos años, y tan sólo parece conservarse un edifico en el interior del recinto fabril.

En primer lugar hay que referirse al edificio fabril más antiguo del sector, aunque en sus orígenes tuviera otra orientación productiva. Efectivamente, el conjunto de edificaciones conocido como La Lechera en la margen derecha del río Besaya en Torrelavega no fue en realidad en su origen una
La otra fábrica centenaria del sector se localiza en Cóbreces, conocida originalmente como Instituto Agrícola Quirós (figura 12), dedicada desde 1907 a la fabri- 

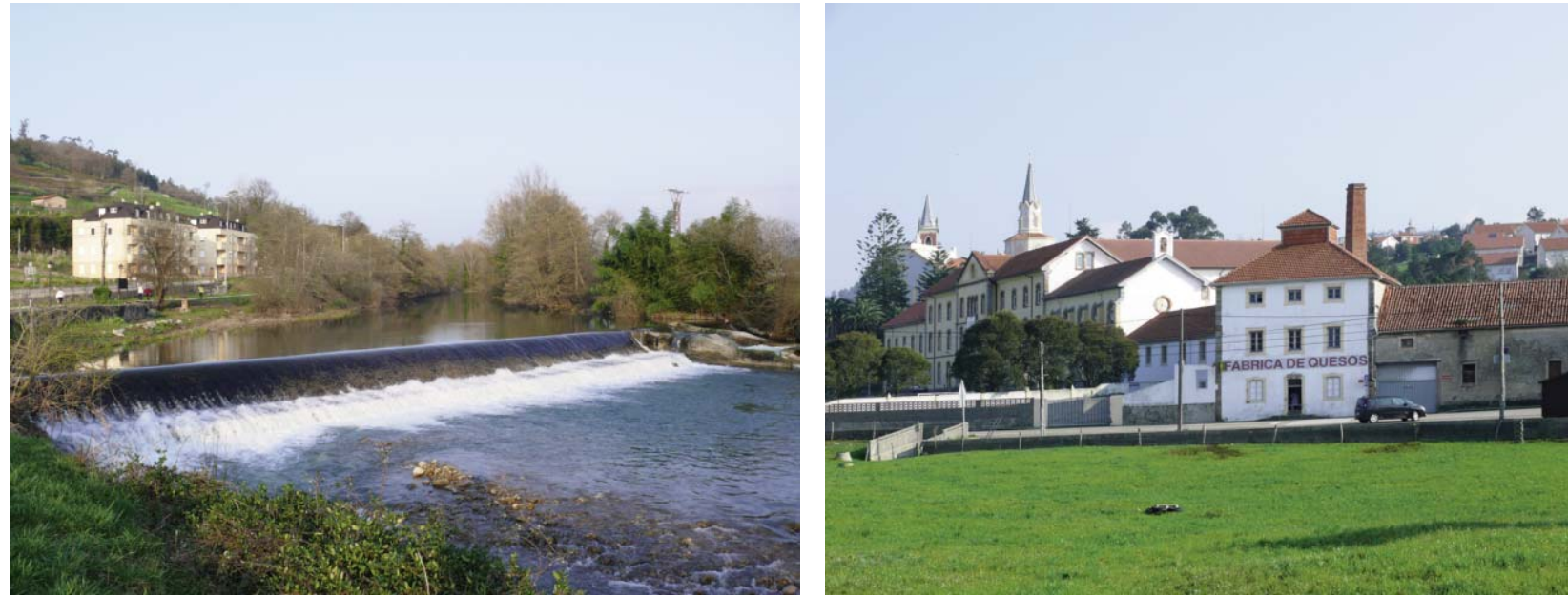

Izquierda. Figura 11 Azud para la fábrica Nestlé. La Penilla de Cayón. Colección del autor, 2016.

Derecha. Figura 12. Fábrica de quesos del Instituto Agrícola Quirós. Cóbreces. Colección del autor, 2016.

Izquierda. Figura 13. Fábrica de Nestlé. Udalla. Colección del autor, 2013

Derecha. Figura 14. Fábrica de Industrias Lácteas del Asón.

Ramales de la Victoria. Colección del autor, 2016. cación de quesos por los Padres Trapenses, quienes continúan haciéndolo de forma tradicional (Casado 2000: 116-119). La fábrica se encuentra en el interior del recinto monacal, donde aparte de un cartel anunciador, la chimenea troncopiramidal de ladrillo revela su existencia.

Sin abandonar el pueblo de Cóbreces, en 1953 en la finca El Castro se comenzó la fabricación de queso y mantequilla, ampliando posteriormente la producción a la leche concentrada. Hasta su cierre en 1998 pasó por diversos propietarios como La Lactaria Española, Central Lechera de Cóbreces y Central Lechera Asturiana (Casado 2000: 120-121). Actualmente mantiene en pie sus naves, pero si observamos su evolución reciente por medio de fotografia aérea se aprecian algunos desperfectos en su cubierta.

En los años veinte Nestlé comenzó una política de expansión con nuevas líneas de producción, con la absorción de otras empresas lácteas e incluso con la construcción de nuevos centros, como el abierto en Udalla en 1928 (figura 13) para ampliar su mercado ganadero al valle del
Asón. La fábrica con una idónea ubicación junto al río y a la línea del Ferrocarril Santander-Bilbao se encuentra actualmente abandonada, no obstante su recinto cubierto se utiliza aparentemente como cuadra para el ganado, lo que sin duda habrá frenado su deterioro. El conjunto aparece presidido por una gran chimenea de ladrillo con el nombre de Nestlé escrito verticalmente.

También junto al río Asón, pero en Ramales de la Victoria, se encuentra la fábrica de Industrias Lácteas del Asón (figura 14), que fue construida en 1955 por Fausto Martín Sanz, propietario de otra fábrica láctea en Palencia, y que cerró sus puertas en 1994 (Casado 2000:). La empresa comercializaba sus productos bajo la marca Botella Blanca, cuyo logotipo puede apreciarse muy decolorado en las paredes exteriores de una de sus tres naves. Las dos décadas de inactividad han afectado de manera notable al conjunto, como se manifiesta en el derrumbe de sus cubiertas y sobre todo en el brutal vandalismo que ha sufrido su interior. En el conjunto sobresale la gran chimenea de ladrillo.
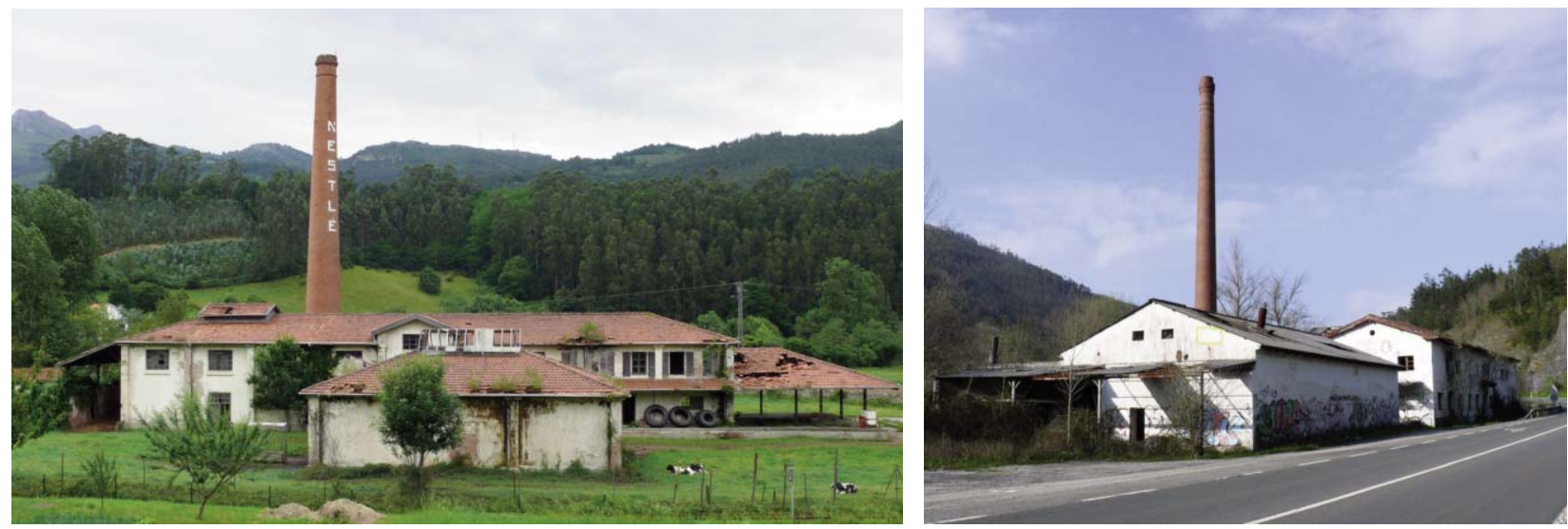


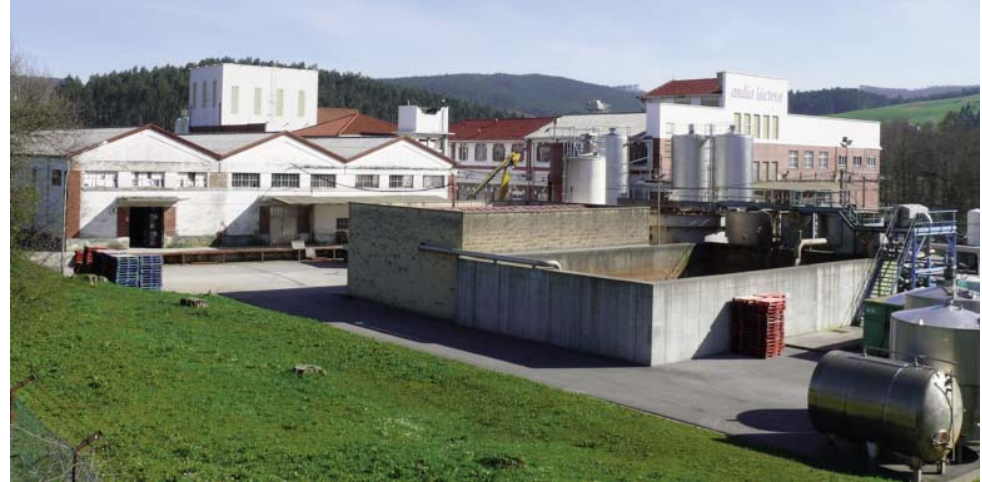

Figura 15. Fábrica de SAM. Renedo de Piélagos. Colección del autor, 2015.

Figura 16. Fábrica de Lecherías Collantes. Bárcena de Pie de Concha. Colección del autor, 2006.

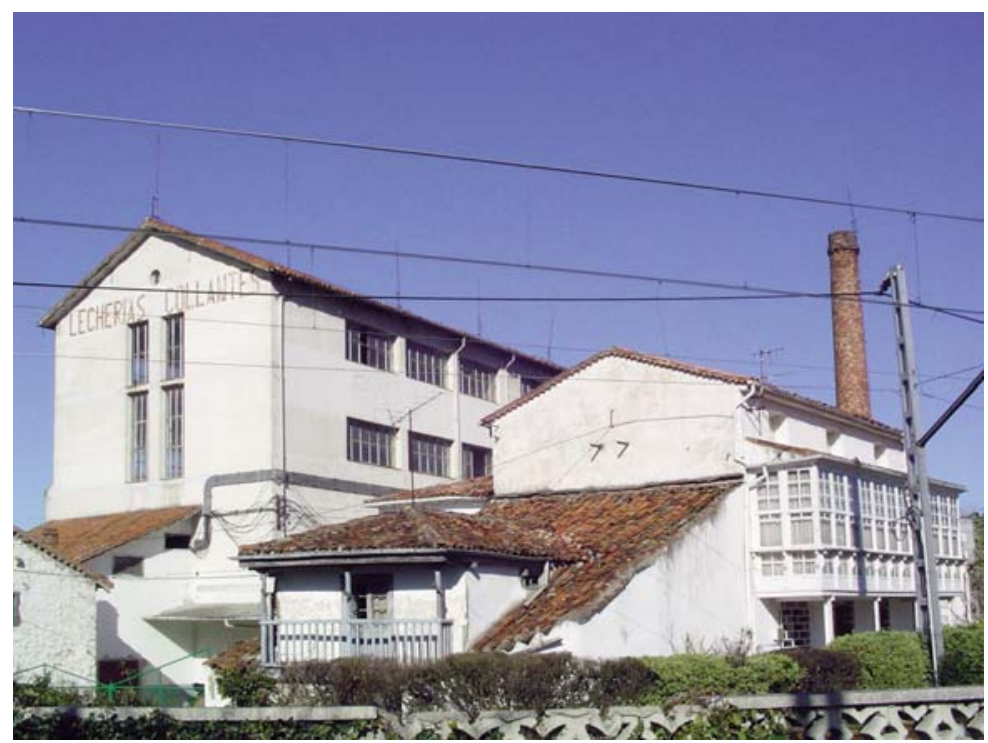

se conserva una pequeña construcción que hubo de ser en su momento la portería de acceso.

En el valle medio del Besaya se localizan dos fábricas que tuvieron un origen e historia muy similar, si bien en la actualidad una se encuentra en actividad y la otra abandonada. La primera es la antigua Lácteos Morais, que actualmente pertenece al grupo francés Andros. Su origen nos lleva hasta 1916 cuando el farmacéutico local instaló en La Serna de Iguña una pequeña fábrica de quesos y mantequillas (Casado 2000: 85). El recinto fabril actual se empezó a utilizar en 1943 cuando comenzó la producción de leche pasterizada, pero se ha transformado de tal manera que resulta muy complicado reconocer, si existieran, vestigios de los primitivos edificios.

En Bárcena de Pie de Concha Luis Collantes comenzó en 1908 la elaboración de quesos y mantequillas y veinte años más tarde la de leche pasterizada (Casado 2000: 90-91). Tras dificultades económicas sus últimos propietarios cerraron la fábrica en torno a 1990. El espacio fabril se encuentra dividido en dos por una carretera local. El más próximo a la estación del ferrocarril sería el más antiguo y también el más abigarrado en planta, ya que incluso hay algún edificio residencial adosado a la nave principal (figura 16). Esta nave, la de mayor altura, mantiene el rótulo pintado con el nombre de la empresa, Lecherías Collantes, y sería la más antigua del conjunto si nos fiamos de su cubierta de teja, mientas en las restantes naves y muelles de carga se utilizó uralita. Una chimenea de ladrillo destaca en el conjunto. Las naves del otro lado del camino parecen construidas simultáneamente a los muelles de carga y descarga y su uso nos es desconocido, si bien la presencia de una chimenea de ladrillo y unas calderas en el exterior apuntan que albergaría la maquinaria que proporcionaba energía a la fábrica.

A partir de 1963 Lecherías Collantes dispuso de otro centro fabril en Cantabria. Desde esa fecha comenzó la producción de leche pasterizada en las instalaciones que había construido El Irati para la fabricación de destilados de madera junto al río Miera en Villaverde de Pontones, aunque dentro de los límites del municipio de Entrambasaguas (figura 17). La fábrica cerró a finales de los años noventa ya en manos de la Corporación Alimentaria Fuensanta (Casado 2000:). Hace unos años se instaló en el recinto una empresa que se dedica fundamentalmente a la fabricación de pellets de madera. Se nece- 


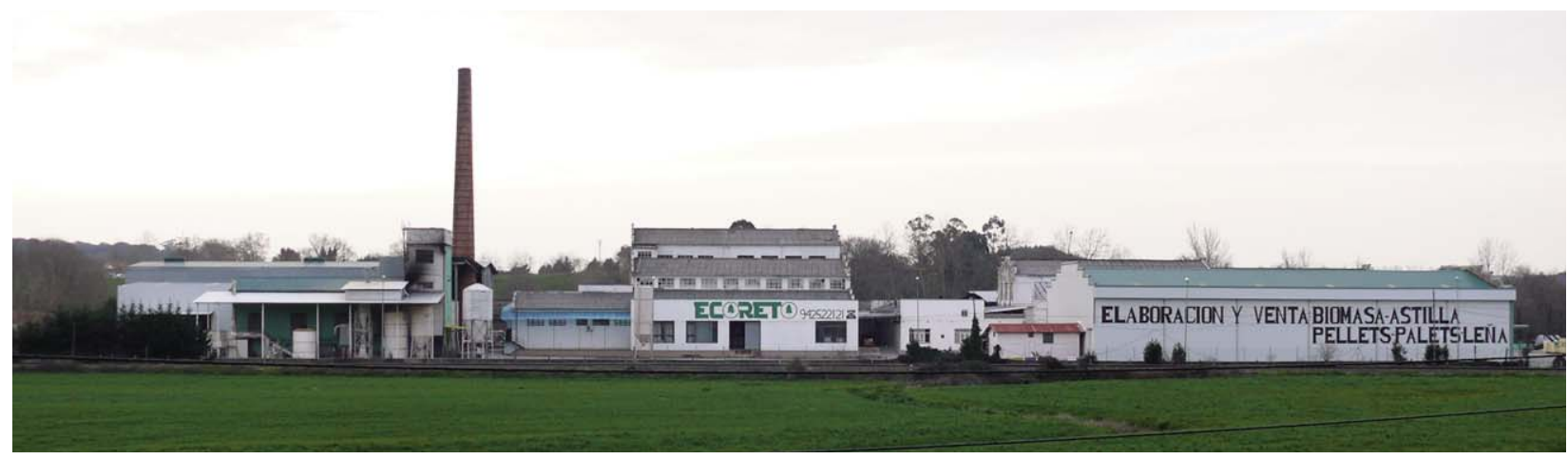

Figura 17. Fábrica de Lecherias Collantes. Villaverde de Pontones. Colección del autor, 2016.

Figura 18. Fábrica de Dietéticos Max. Entrambasaguas. Colección del autor, 2008.

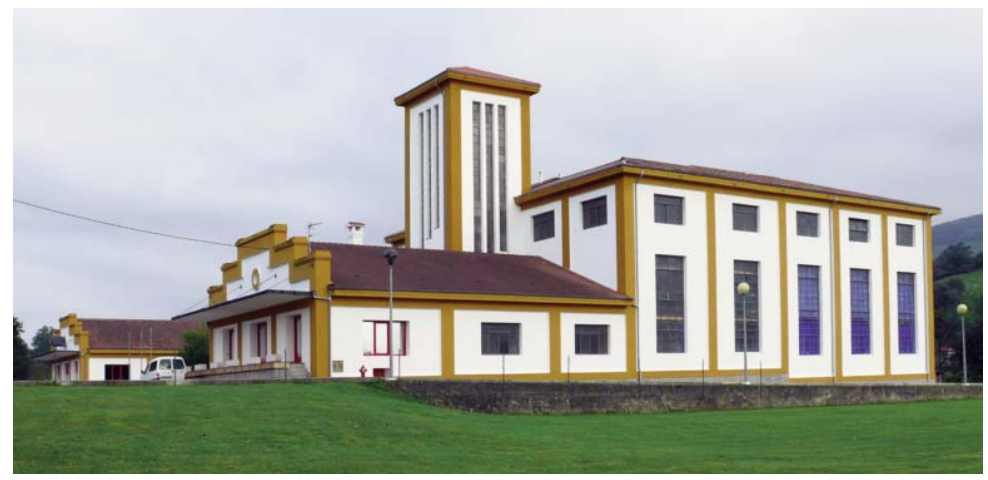
fue un centro de recogida de leche de CLESA (Casado 2000:). Actualmente se encuentra muy transformado ya que se utiliza como almacén. Un azud próximo pudo servir en su momento para abastecer de agua a la fábrica.

Sin abandonar el municipio de Entrambasaguas hemos de reseñar un establecimiento fabril que nunca llegó a funcionar como tal pese que se realizara enteramente su construcción. En 1936, justo cuando se inició la Guerra Civil, se estaba esperando la maquinaria que se había adquirido en diferentes puntos de Europa para que entrara en funcionamiento la fábrica de Dietéticos Max (figura 18), que se proponía poner en marcha el farmacéutico de origen alemán Max. F. Berlowitz, que desde los años veinte tenía unos laboratorios de productos dietéticos en el centro de Madrid. La maquinaria se instalaría tras la guerra, pero al poco tiempo fue vendida a
Nestlé y SAM, quienes nunca estuvieron interesados en ponerla en marcha. El edificio se transformó en los años ochenta en discoteca y en la actualidad es un albergue juvenil (Cueto 2009). Lógicamente sus nuevos usos implicaron que se eliminaron todos los vestigios industriales y se modificara su distribución interior, pero por el contrario han contribuido a mantener su aspecto exterior en perfecto estado. Asimismo, es posible apreciar una pequeña obra hidráulica para la captación de agua en el río Aguanaz.

En Liaño de Villaescusa funcionó desde 1966 una pequeña fábrica que pasó por diferentes dueños como Lerresa, Copeleche o Quesos Frias hasta su reciente cierre, que ha permitido la conservación del conjunto con sus elementos perfectamente reconocibles.

No podemos terminar el recorrido por el patrimonio industrial lechero sin referirnos a los puestos de recogida de leche que jalonaron las carreteras de Cantabria y que formaban parte de su paisaje cuando el transporte de leche se realizaba en ollas de aluminio que eran recogidas por los camiones de las empresas lácteas. Estas pequeñas estructuras generalmente de planta cuadrada fueron el lugar de encuentro de los ganaderos que depositaban en ellas sus ollas. Desde que obligatoriamente se tuvo que realizar el transporte en camiones cisterna dejaron de tener utilidad, por lo que su deterioro fue inexorable. En muchos casos las ampliaciones de las carreteras también han contribuido a su desaparición. Convendría en este momento realizar un inventario de los puestos de recogida que todavía se conservan en Cantabria.

\section{La industria conservera de pescado}

Antes de que se establecieran en Cantabria las primeras fábricas trasformadoras de pescado ya se empleaban diversas prácticas de conservación de tipo artesanal que retardaban la descomposición del pescado, 
facilitaban su consumo fuera de temporada y posibilitaban su traslado a lugares lejanos, como el salazón y el escabechado (Ansola 1999: 301). El escaso desarrollo urbano de Cantabria y las dificultades de acceso de pescado fresco al mercado interior castellano impusieron como necesidad la transformación del pescado (Ortega 1996: 133).

Las primeras fábricas de conservas se instalaron en los años cincuenta del siglo XIX y tuvieron un rápido desarrollo que hizo pasar a un segundo plano a las escabecherias, quedando consolidado en el cambio de siglo con el resurgimiento de la técnica del salazón y la dispersión territorial de las empresas conserveras. La llegada a finales de siglo de salazoneros italianos a la costa cantábrica en busca de anchoa está en el origen de esta nueva orientación (Escudero 2007), ya que muchos empresarios locales siguieron su ejemplo e incorporaron a su gama de productos la anchoa en salazón y sobre todo la semiconserva de anchoa. Los factores que justifican esta especialización fueron varios: la facilidad para la puesta en marcha de las fábricas, cuyo proceso era totalmente manual, la abundancia de materia prima poco explotada por su escaso valor comercial, la disponibilidad de una flota adaptada a la captura de la anchoa y la existencia del consolidado mercado de consumo italiano (Escudero 2007: 31-32). Tras la Guerra Civil el sector vivió un momento crítico; el aceite y la hojalata empleados por la industria se vieron sometidos a cupos que no alcanzaban a cubrir las necesidades de la industria y que se mantuvo al menos durante los años cuarenta. Mucho más perjudicial para el sector fue la restricción de las exportaciones, cuyo mercado quedó reducido a España. Esta situación afectó especialmente a las fábricas de salazón, por cuanto era un producto destinado integramente a la exportación; la única solución para no perder la materia prima fue su transformación en filete con destino al mercado nacional (Escudero 2007: 179).

No obstante, el sector pudo aguantar esta época de crisis, de la que saldría en los años sesenta, en la que la especialización del sector fue mucho más acusada, centrándose en filete de anchoa envasado en aceite. De esta manera quedó a expensas de un solo producto y una sola costera. Lo que no cambió fue la atomización del sector y la escasa presencia de grandes empresas (Ansola 1999: 316-320).

Paseando por los puertos pesqueros de Cantabria todavía es posible descubrir vestigios de la industria conservera manifestada en viejas naves industriales abandonadas, una vez que la normativa comunitaria obligó a las empresas a trasladarse a nuevas naves en modernos polígonos industriales. La localización costera en terrenos muy apetecibles urbanísticamente ha hecho desaparecer en este tiempo muchos de aquellos inmuebles. En general, no se trataba de edificios de gran interés arquitectónico, pero sí con un valor histórico, social y simbólico muy apreciable.

En Castro Urdiales quedan pocas huellas de sus fábricas más antiguas. De hecho, su fábrica más emblemática, Conservas Lolín, ocupa un gran edificio de nueva construcción. No obstante, en la zona de Los Huertos podemos encontrar la antigua fábrica de Antonio Cefalú, con una curiosa planta adaptada la curva del terreno, que hoy tiene uso como almacén. Seguramente en otros puntos de la villa haya algún otro vestigio ya que no era infrecuente que las fábricas se localizaran en los bajos de edificios de viviendas.

Laredo sufrió hace unos años una sensible pérdida patrimonial cuando la fábrica de Conservas Salvarrey, obra del arquitecto Eladio Laredo en 1907, fue derribada para construir un bloque de viviendas en su privilegiado solar. Aunque los ejemplos no son muchos, todavía queda la huella de otros establecimientos conserveros en la zona portuaria: la fábrica de la familia Giannitrapani es ocupada hoy por un supermercado; las naves que fueron utilizadas por la fábrica de Vincenzo Marino se encuentran abandonadas; lo mismo que las que en la misma manzana tiene la conservera Rezumar.

Santoña se convirtió a principios del siglo XX en la capital conservera del Cantábrico, ya que fue el puerto elegido por los salazoneros italianos para acopiar la anchoa antes de enviarla a su país. Así, un puerto con menor tradición pesquera que los anteriores fue poco a poco acumulando fábricas conserveras hasta llegar a ser el más conocido del Cantábrico por esta orientación. Aunque tras el traslado de la fabricación al polígono industrial se han ido perdiendo vestigios de las primeras conserveras aun quedan algunas junto al viejo puerto pesquero. Un paseo por esta antigua zona fabril nos permite reconocer testimonios de diferentes etapas históricas y a la vez constatar la importancia que la industria tuvo, y por supuesto mantiene, en Santoña. 


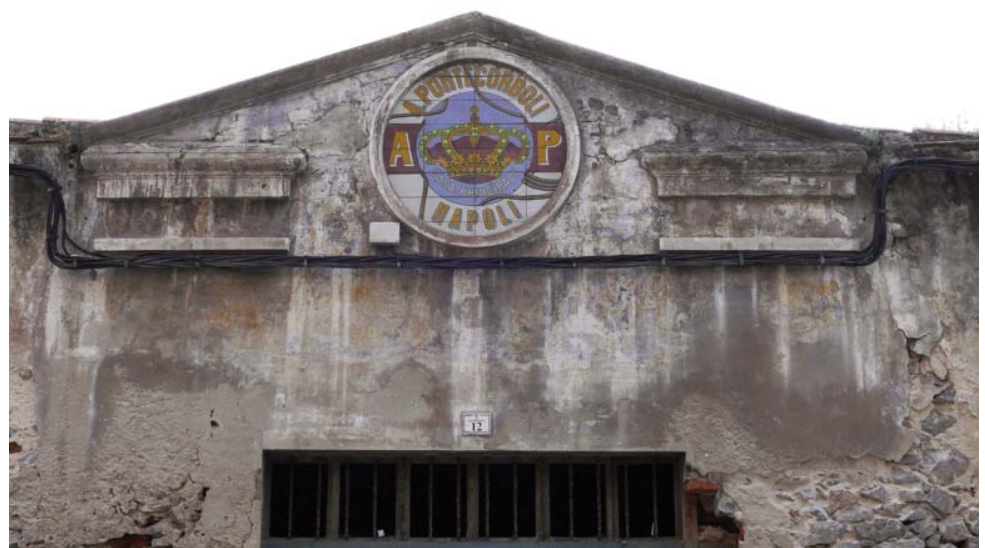

Figura 19. Medallón con el emblema de la conservera $A$.

Pontecorboli. Santoña. Colección del autor, 2011.

Arriba. Figura 20. Fábrica de

Conservas Albo. Santoña. Colección del autor, 2011.

Abajo. Figura 21. Fábrica de Conservas Hoya. Santoña. Colección del autor, 2011
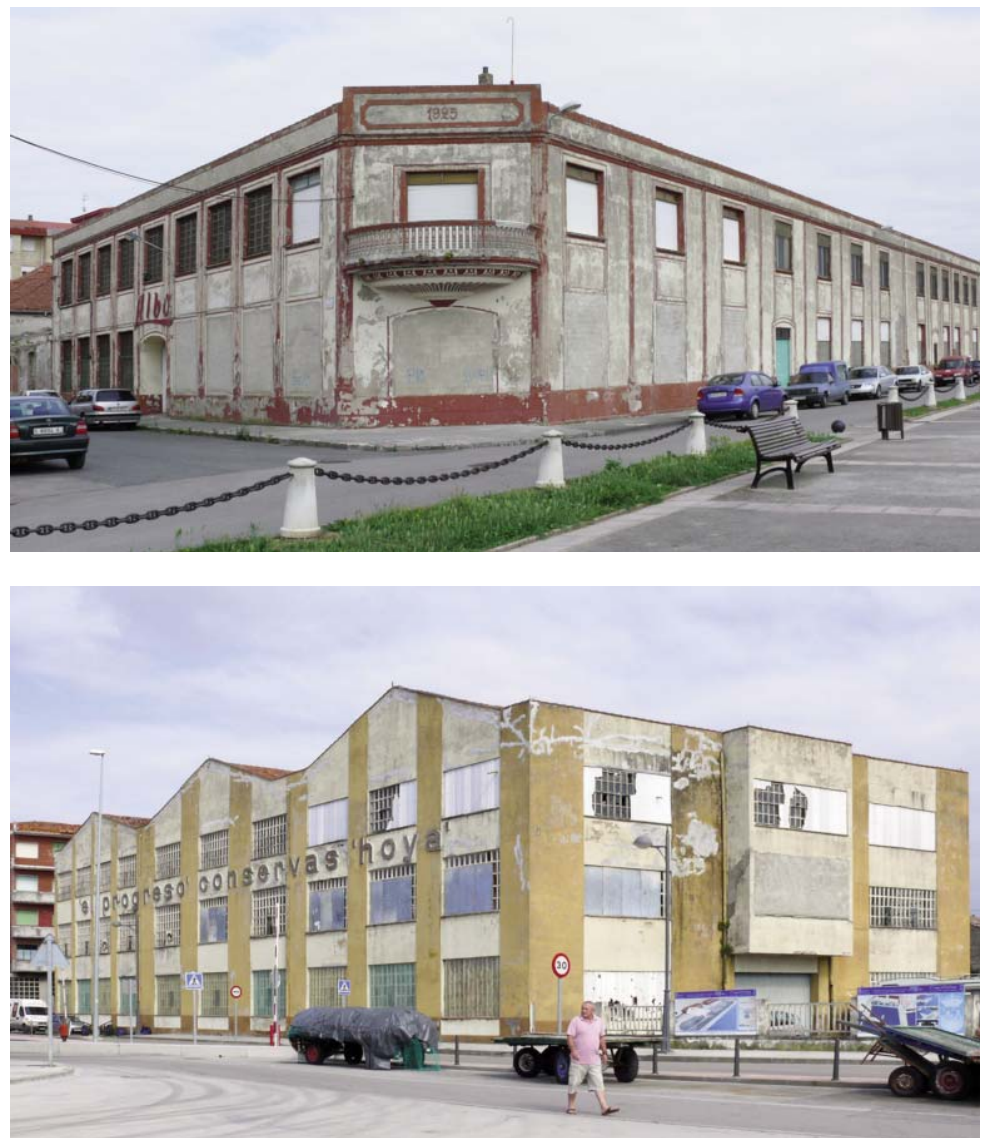

cio de Conservas Albo que ocupa un amplio espacio junto al puerto en el que destaca el juego de color con el rojo destacado en esquinales, recercos y líneas de relieve sobre el fondo blanco de los paramentos (figura 20). El más antiguo de los dos edificios fue construido en 1925, como se muestra en la fachada de su chaflán, con un balcón semicircular que es la única concesión estética del edificio, aparte del nombre del propietario en varias fachadas, en una de las del edificio más moderno sobre un ventanal que busca asemejarse al cuerpo de un pez.

También de los años veinte es la nave de La Cantábrica, nombre comercial de su primer propietario, aunque fue un edificio que fue utilizado posteriormente por otras conserveras. Tiene una fachada en chaflán, como la de Albo, y un cierto gusto estético en los ventanales de su primera planta.

Como ejemplo de edificios fabriles de los años sesenta destacan dos, el de Conservas Palazzolo con una fachada principal dominada por los ventanales reticulados, que también encontramos en la fábrica de Conservas Hoya, que añade en su fachada principal el nombre comercial de sus productos: El Progreso (figura 21).

Los ventanales industriales reticulados también son relevantes en la fábrica de Conservas San Juan, cuya singularidad, más allá de ser representativa de esa época, es su localización interior, en Gibaja junto a la estación ferroviaria (Sierra 1998: 314). Es uno de los ejemplos que quedan de los años sesenta en que los progresos en los transportes en frío permitieron disociar las fábricas conserveras de los puertos. El edificio en la actualidad es utilizado como almacén.

La búsqueda por la costa cántabra de una nueva conservera nos lleva hasta Comillas, por cuanto ni en Santander ni en Suances se conservan restos identificables de antiguos edificios industriales. Incluso en Comillas el edificio que construyó La Comillana, una conservera impulsada por el Segundo Marqués de Comillas (figura 22), pasa desapercibido para el paseante, por cuanto su uso actual no responde en absoluto al original. El edificio presenta unas grandes dimensiones si lo comparamos con otras conserveras de principios del siglo XX, con cinco naves, únicamente la central de dos alturas (Sierra 1998: 314). Aunque en la actualidad se ha descubierto la mampostería de sus paramentos, originalmente estaban enfoscados, lo que resaltaría aún más la utilización de 


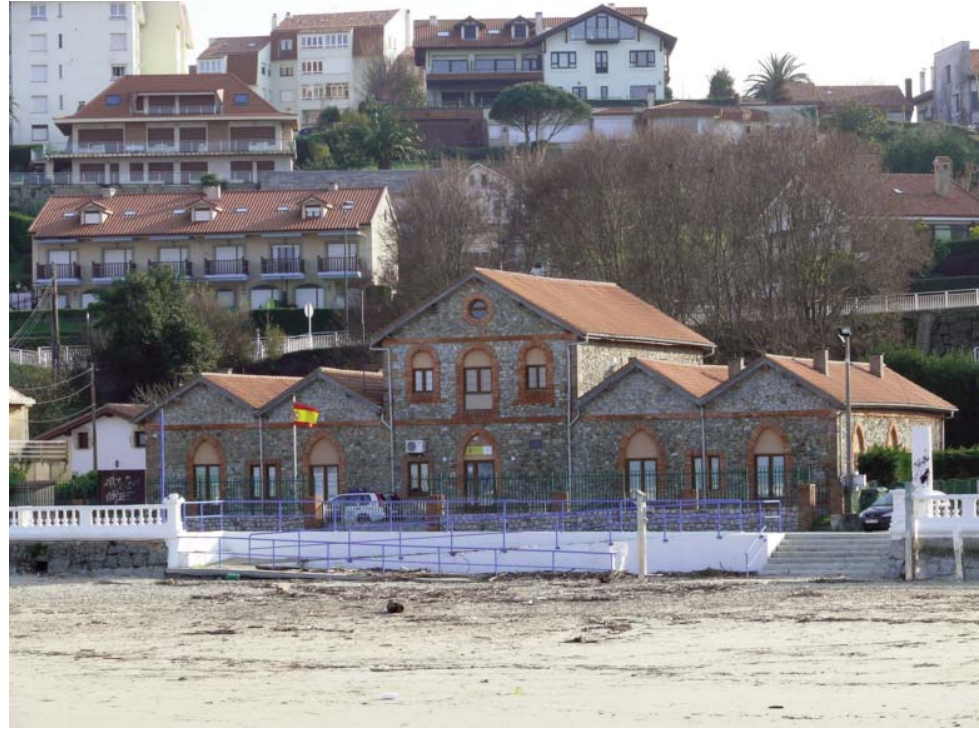

Figura 22. Fábrica de Conservas La Comillana. Comillas. Colección del autor 2016

Figura 23. Fábrica de Conservas Ortiz San Vicente de la Barquera. Colección del autor, 2008

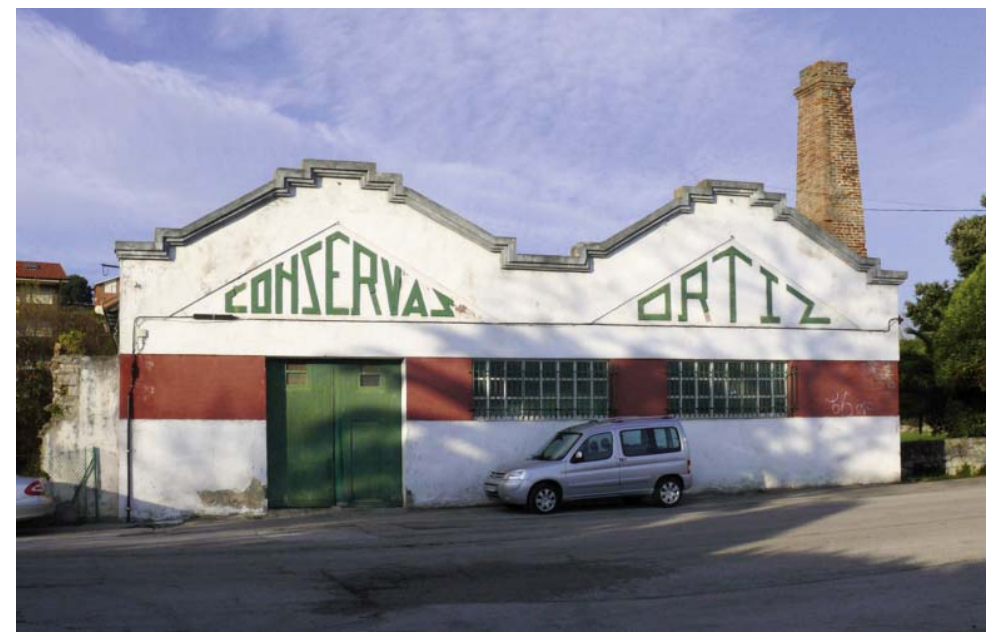

cional, aunque la fábrica continúa elaborando filetes de anchoa en aceite.

En el limite con Asturias, de hecho en la margen derecha de la ría de Tinamayor que separa ambas comunidades autónomas, se encuentra un edificio que aparentemente resultaria complicado asignarle un pasado industrial. La fábrica de Conservas Noriega se construyó a comienzos del siglo XX y mantuvo su actividad hasta finales de los años cuarenta. Su lejanía con respecto al puerto explica la existencia de un pequeño embarcadero por el que recibía la materia prima. La antigua conservera está formada por dos naves de producción perpendiculares a una tercera que tenía función administrativa y residencial.

\section{La fábrica de tabacos de Santander}

La producción de tabacos había estado concentrada en las Reales Fábricas de Sevilla, con la excepción de Cádiz y otros pequeños establecimientos hasta que a principios del siglo XIX se decidió la creación de nuevas fábricas en otros puntos del país para atender a nuevas producciones, reducir los costes de distribución y buscar centros de trabajo de menor tamaño para amortiguar las reclamaciones obreras. Una de las nuevas fábricas se instaló en Santander en 1821 en una de las salas del hospital civil, que cerró al poco tiempo para reabrir definitivamente en 1835 en un espacio más amplio como era el antiguo convento de Santa Cruz del Monte Calvario (Comin y Martín Aceña 1999: 74-77).

La manufactura de tabacos en Cantabria no es sólo una de sus primeras manifestaciones industriales, más bien protoindustriales, sino que todavia mantiene su actividad tras casi dos siglos. Aunque en sus inicios la fábrica de tabacos no ocupara un edificio propio, pasado el tiempo el viejo convento acabó por convertirse en un verdadero edificio industrial sobre todo si tenemos en cuenta que desempeñó este uso durante más de 160 años, de manera que las cigarreras ocuparon casi tanto tiempo el edificio como la religiosas. La producción de la fábrica fue creciendo constantemente, de la misma manera que lo hacia su plantilla, femenina en su mayoría, que superaría el millar de cigarreras a mediados de siglo, muy significativo en una ciudad como Santander que contaba entonces con una población total de unos 30.000 habitantes. Por tanto dentro del sector agroalimentario era la única fábrica que alcanzaba la envergadura propia de una gran empresa, pese a que el sistema de producción fuera fundamentalmente 

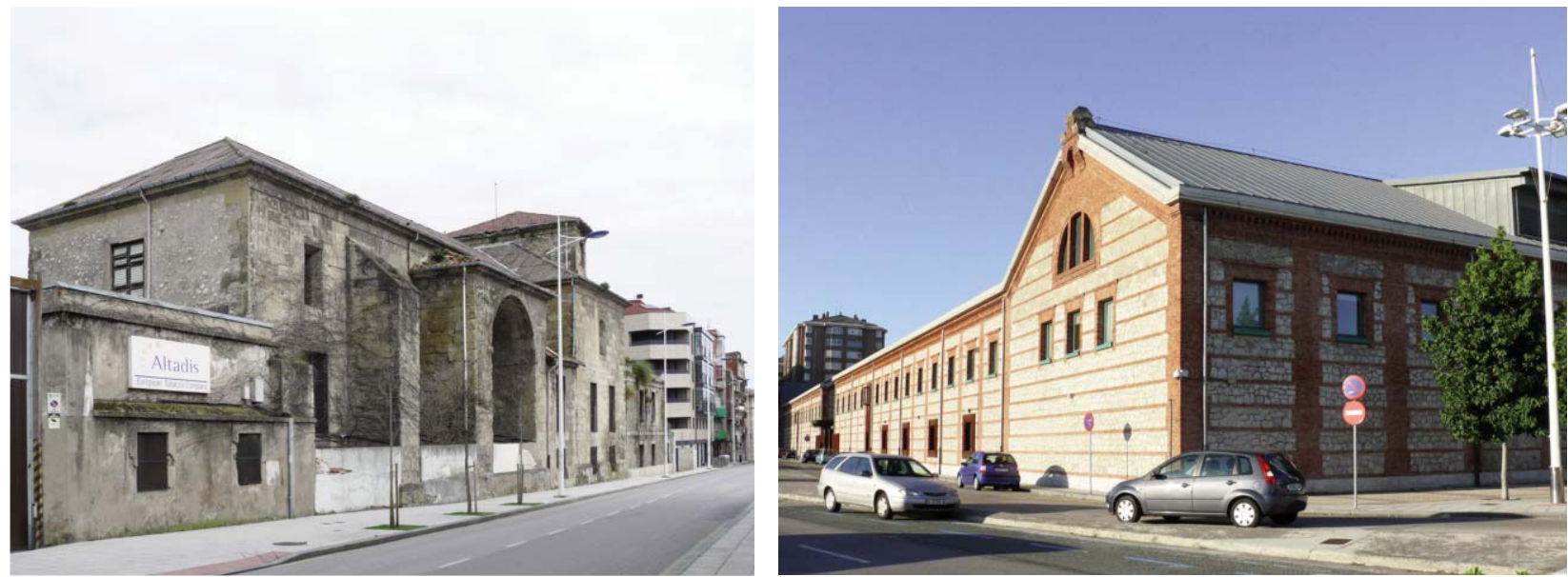

Izquierda. Figura 24. Fábrica de tabacos, antiguo convento de Santa Cruz del Monte Calvario. Santander. Colección del autor, 2016.

Derecha. Figura 25. Depósito de tabacos en rama, actual Regional. Santander. Colección del autor, 2013. de Elaborados de Tabacalera. Santander. Colección del autor, 2006.
Archivo y Biblioteca

Figura 26. Depósito

manual (Ortega 1986: 157-158; Hoyo 1993: 188-190).

El edificio quedó abandonado una vez que las cigarreras se trasladaron a la moderna fábrica de Entrambasaguas en 2002 y poco a poco se ha ido deteriorando, no sólo el viejo convento, sino también los nuevos espacios productivos que se fueron incorporando al centro fabril (figura 24). Existe un proyecto desde hace unos años para utilizar una parte del recinto para la construcción de viviendas, pero todavía no se ha materializado.

Aparte de este edificio manufacturero, la producción de tabaco en Santander ha legado otros dos edificios de gran interés.

En 1899 se concluyó la construcción del depósito de tabacos en rama sobre los terrenos ganados al mar por la concesión Wissocq (figura 25). Con un atractivo estilo mudéjar que juega con el ladrillo y la mampostería para dejar que en sus dos accesos sea el ladrillo el que haga el juego

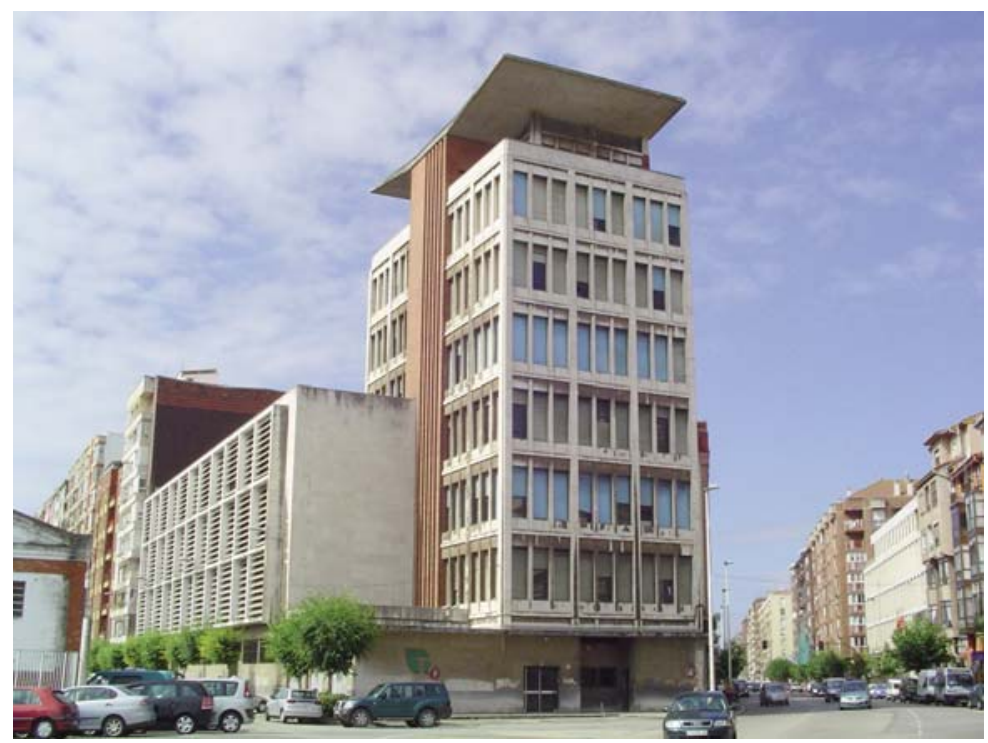

de luces y sombras. Desde luego era un edificio de grandes dimensiones que sobrepasaba las necesidades de la fábrica local, que quedaba justificado ya que servía de depósito para el resto de fábricas del país. En 1986 se pensó en este edificio como sede del Gobierno de Cantabria, pero finalmente esta idea no cuajó. Afortunadamente años más tarde el Gobierno Regional decidió recuperar esta joya arquitectónica para convertirla en el Archivo Histórico Provincial y Biblioteca Regional de Cantabria, según un proyecto firmado por los arquitectos Luciano Moreno, Eduardo de la Torre y Ricardo Urech. Las obras para su acondicionamiento comenzaron en junio de 2001 y se dilataron en exceso en el tiempo, de manera que hasta diciembre de 2009 no pudo ser inaugurado oficialmente. Hoy el archivo y la biblioteca cuentan con una magnífica sede que ocupa más de 20.000 metros cuadrados que también dispone de salas para exposiciones y para todo tipo de actos, así como de una gran plaza interior (Cueto 2014: 293).

Muy próximo a este edificio se encuentra el Depósito de Elaborados de Tabacalera (figura 26) formado por dos volúmenes maclados, el de almacén y una torre de seis plantas, construido en 1958 según un proyecto de Juan José Rasines del Castillo. Cuando se presentó el proyecto de remodelación del frente marítimo se eligió este edificio como sede de las oficinas portuarias (Cueto 2014: 294). No obstante, esta opción quedó descartada, pero de nuevo ha surgido una propuesta para el edificio, en este caso para utilizarlo como centro cívico.

\section{Otros sectores industriales y patrimo- nio vinculado}

Una vez reseñada la huella del pasado industrial de los principales ramos de la industria agroalimentaria cántabra, 


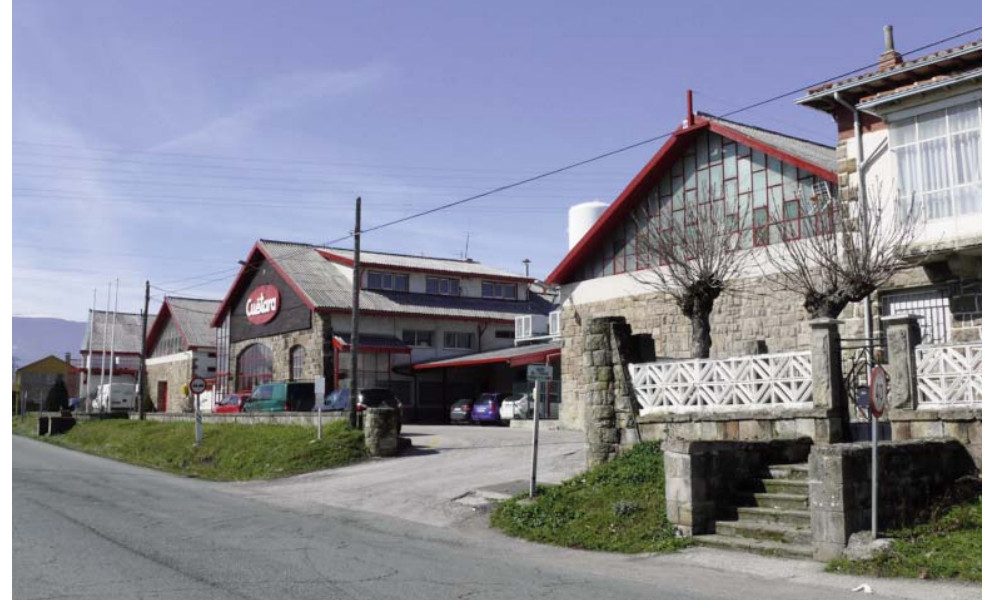

Figura 27. Fábrica de galletas Cuétara. Reinosa. Colección del autor, 2016.

hemos agrupado en un único epígrafe otros vestigios de industrias con menor arraigo en la región y lo que podemos englobar como patrimonio industrial vinculado, como los mercados de abastos donde se intercambiaban los productos agroalimentarios, las lonjas de pescado, mataderos, etc.

Eso sí, antes de avanzar en el desglose de este patrimonio es ineludible indicar que uno de los ramos más característicos de la historia industrial de Cantabria como el cervecero carece actualmente de restos físicos. La tradición cervecera de la región y particularmente de su capital viene de finales del siglo XVIII, gracias a las ventajas concedidas al puerto de Santander para el comercio ultramarino que permitió a Cantabria monopolizar este comercio gracias a las tres fábricas que había asentadas en la ciudad (García Barber 2015). Tras la emancipación americana el sector se sumió en el olvido hasta que se revitalizó en el último cuarto de siglo con la instalación de dos grandes fábricas en Santander: La Cruz Blanca, de capital suizo, en 1878 y La Austriaca, de capital local, en 1884. Gracias a una eficaz politica de expansión ambas alcanzarian un gran reconocimiento a nivel nacional, aparte del que tenían en las colonias americanas. En 1917 ambas se fusionaron en una nueva empresa: Cervezas de Santander. La fábrica de La Cruz Blanca, última superviviente, cerró en los años ochenta y fue demolida, de manera que su recuerdo se remite a un topónimo popular, ya que una parte del solar que ocupó es conocido como "la plaza de las cervezas" aunque oficialmente no aparezca así en el callejero.

Hemos descrito la importancia del ramo harinero, pero también en Cantabria hubo una serie de establecimientos industriales que se ocuparon de la transformación de la harina junto a otras materias primas en pastas, galletas, pan, etc. En la mayor parte de los casos se trató de pequeños establecimientos de carácter familiar que no llegaron a constituir edificios propios y se asentaban en los bajos de la vivienda familiar. Queremos destacar dos de ellos que, a su vez, representan dos momentos históricos diferentes. La Providencia era una fábrica de pan en Astillero de principios del siglo XX que abastecía también a los pueblos circundantes. El edificio que ocupó mantiene su aspecto exterior aunque su uso ha variado, ya que su planta baja está ocupada por establecimientos de hosteleria, mientras las plantas superiores tienen uso residencial como seguramente tuvieron cuando estaba en actividad. Su ubicación en el centro de la población y su torre cilindrica de tres pisos le confieren un notable interés. La otra fábrica que queremos destacar es la de Cuétara en Reinosa (figura 27), por dos razones: la importancia que la industria galletera tiene en la comarca de Campoo y su estética que dista mucho de otros establecimientos industriales de Cantabria, cuya fachada se podría incluir en un estilo montañés con una hábil y estética combinación de la piedra, el vidrio y la madera que consigue edulcorar el uso industrial del edificio.

La producción industrial de bebidas espirituosas tuvo su importancia en el pasado para el abastecimiento de licores y otras bebidas alcohólicas a los centros urbanos. Por tanto, lo más frecuente era que tuvieran una localización urbana, sin embargo el establecimiento al que nos vamos a referir se ubicaba en un núcleo rural, incluso alejado de centros urbanos. La Destilería Santa Marina comenzó a producir aguardientes y licores, especialmente anis y coñac, en 1903 en Udalla aprovechando un salto de agua del río Asón. En este pueblo del municipio de Ampuero se conservan algunos edificios que pertenecieron a la licorera, entre los que merece resaltar un edificio de tres plantas en el centro del pueblo que exhibe de manera destacada el nombre más conocido de sus producciones: Anís Udalla.

Dando un salto en el tiempo y en el espacio nos situamos en el puerto de Santander, en concreto en la zona de Varadero, que durante décadas albergó naves industriales, muchas de ellas simples almacenes portuarios, hoy abandonadas. La Nave Sotoliva pertenecía a un establecimiento industrial en el que se procesaba y envasaba aceite de oliva que se recibía por el puerto de Santander (figura 28). Su interés 


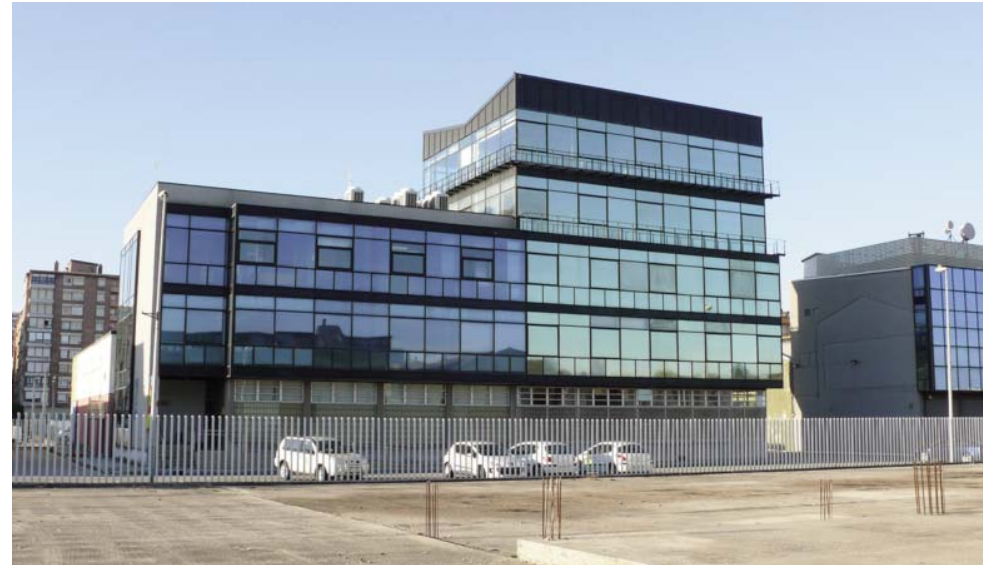

Figura 28. Nave Sotoliva. Santander. Colección del autor, 2013.

Figura 29. Mercado de la Plaza de la Esperanza. Santander. Colección del autor, 2016. reside, por una parte, en que si no se remedía en poco tiempo será el único edificio con pasado industrial de Varadero y, por otra parte, su recuperación como espacio expositivo a principios de los noventa. El edificio original fue obra de Ángel Hernández Morales en 1950, mientras la reforma fue llevada a cabo por Jerónimo Junquera y Estanislao Pérez Pita, quienes aparte de resaltar la torre de vidrio de cinco plantas acondicionaron el espacio productivo como sala de exposiciones que durante muchos años cumplió esta función, aunque desgraciadamente no en la actualidad.

Los mercados de abastos, las lonjas de pescado, los mataderos... son elementos patrimoniales vinculados a la industria agroalimentaria que en muchas ocasiones siguen manteniendo su uso original, lo que ha permitido su conservación. En Cantabria podemos encontrar ejemplos destacados de estos elementos de finales del siglo XIX y principios del XX.

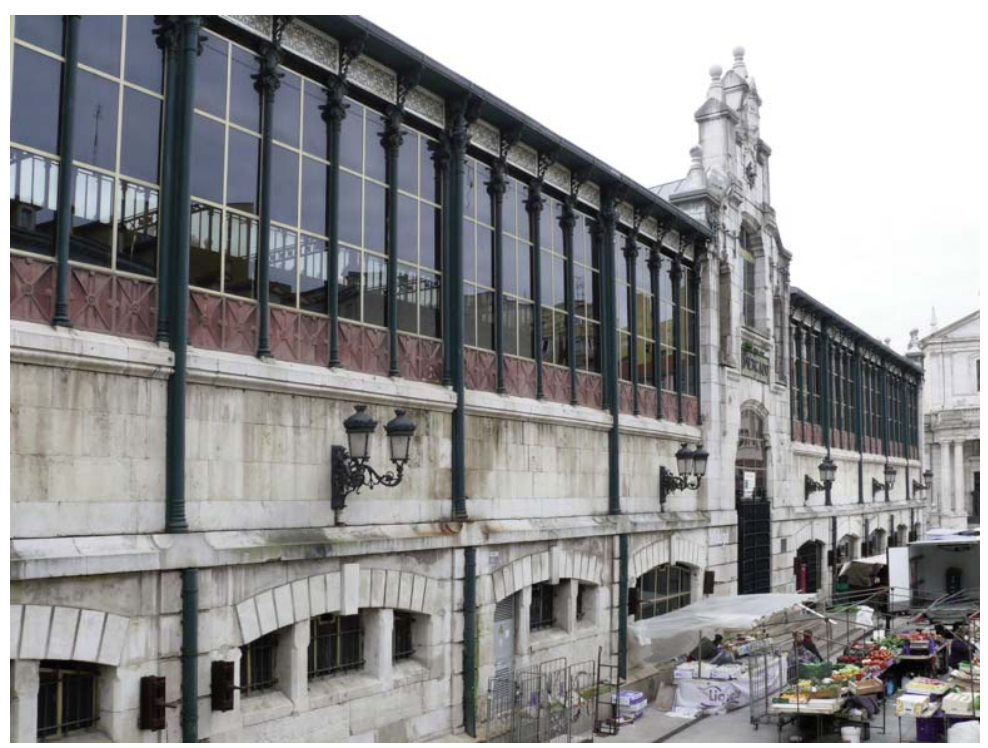

En Santander fueron desapareciendo muchos de estos antiguos mercados, algunos muy recientemente, de manera que escasean los edificios antiguos vinculados a la industria agroalimentaria. En 2000 el Mercado del Este, pese a tener la categoría de BIC, fue demolido y reconstruido empleando nuevos materiales para albergar diversos establecimientos comerciales y en unos nuevos sótanos el Museo de Prehistoria y Arqueología de Cantabria. En 2004 se construyó la nueva lonja que dejó en desuso a la antigua de 1952, uno de los pocos ejemplos de arquitectura racionalista de la ciudad, y dos años más tarde fue demolida.

No obstante, junto al ayuntamiento de la ciudad se conserva el Mercado de la Plaza de La Esperanza (figura 29) que continúa abriendo al público para la venta de todo tipo de productos. Se edificó sobre una parte del solar del convento desamortizado de San Francisco en 1904 siguiendo los planos de Eduardo Reynals y Toledo y Juan Moya e Idígoras combinando el uso de la piedra, la madera y el hierro (Sazatornil Ruiz 1996: 99).

Asimismo, se conserva el edificio de la antigua almotacenía, es decir el lugar destinado a peso y subasta del pescado, que fue inaugurada en 1895 según proyecto de Valentín Lavín Casalís. En 1982 fue desmontada y reconstruida dos años más tarde al otro lado de la calle para albergar el Centro Cultural Doctor Madrazo (Sazatornil 1996: 271).

En la costa oriental resulta interesante la obra del arquitecto Eladio Laredo, que se encargó del proyecto de varios equipamientos a los que dotó de un estilo neomudéjar en su Castro Urdiales natal, Laredo y Santoña (Sazatornil 1996: 276-282). En Castro Urdiales es el responsable del Matadero que se finalizó en 1899 y que en la actualidad es la sede del Centro Musical Ángel García Basoco, y del Mercado de Abastos, realizado entre 1908 y 1911 (figura 30). En Laredo proyectó en 1902 el Matadero, del que sólo se conserva su fachada principal por cuanto fue sustituido por una piscina climatizada, y el Mercado de Abastos (figura 31), que en los azulejos de su fachada representa, como era habitual, los productos que se vendian en el interior, como mariscos, ovejas, cerdos, vacas... Similar representación, aunque en relieve, presenta la Plaza de Abastos de Santoña (figura 32), su última obra en esta relación, que se inauguró en 1912 utilizando materiales del desmantelado Mercado de Atarazanas de Santander. 

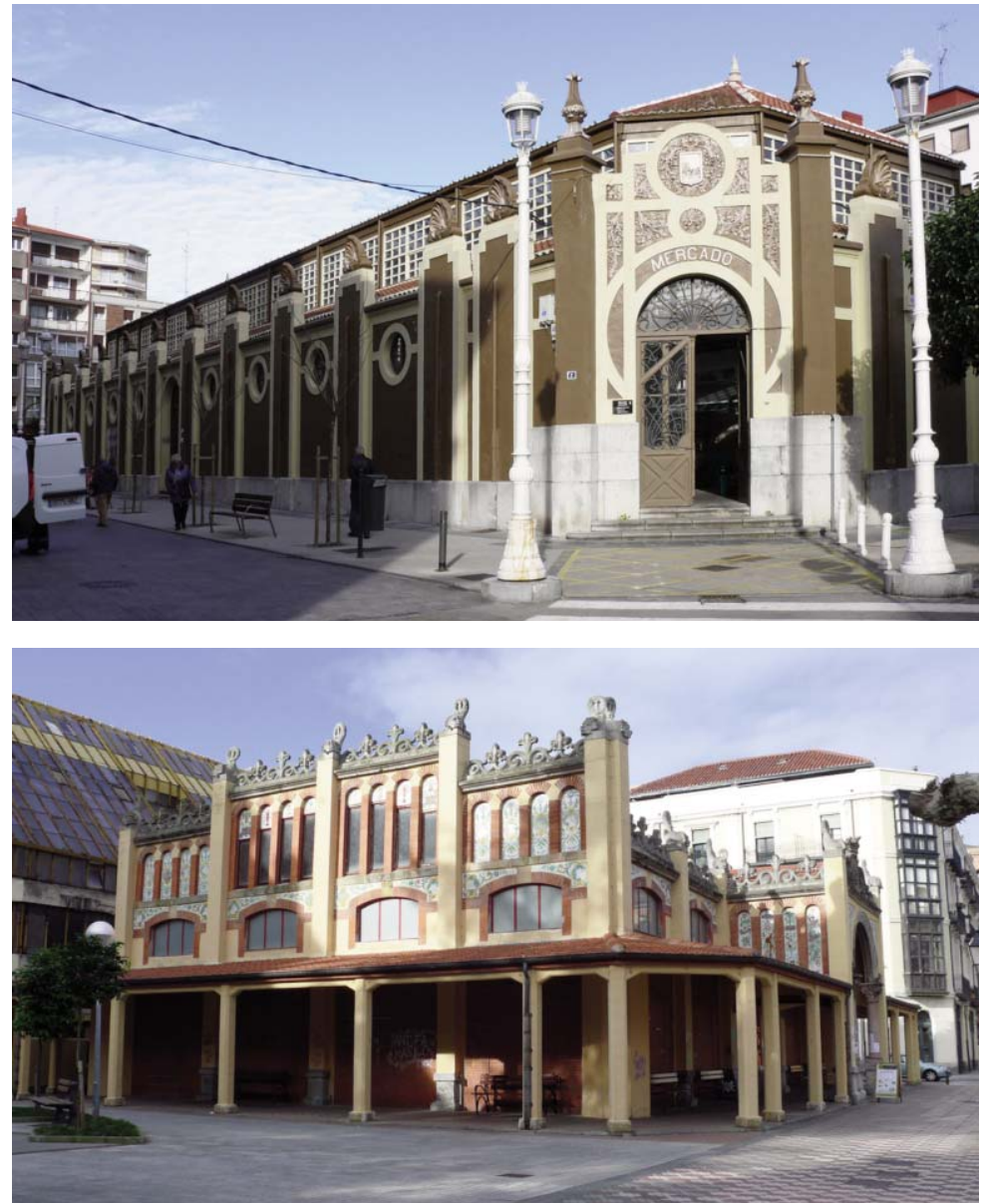

Figura 30. Mercado de Abastos. Castro Urdiales. Colección del autor, 2016.

Figura 31. Mercado de Abastos. Laredo. 2016, autor.

Figura 32. Plaza de Abastos. Santoña. Colección del autor 2011.

\section{Conclusiones}

La huella del sector industrial agroalimentario en Cantabria es apreciable, incluso numéricamente, si bien pasa muchas veces desapercibida para el visitante ocasional e incluso para la población local.

Que una antigua fábrica tenga un nuevo uso, cualquiera que éste fuera (residencial, cultural, turístico, hostelero e incluso industrial) es muy apreciado para los que nos dedicamos a reivindicar nuestra historia industrial como parte de nuestro patrimonio cultural.

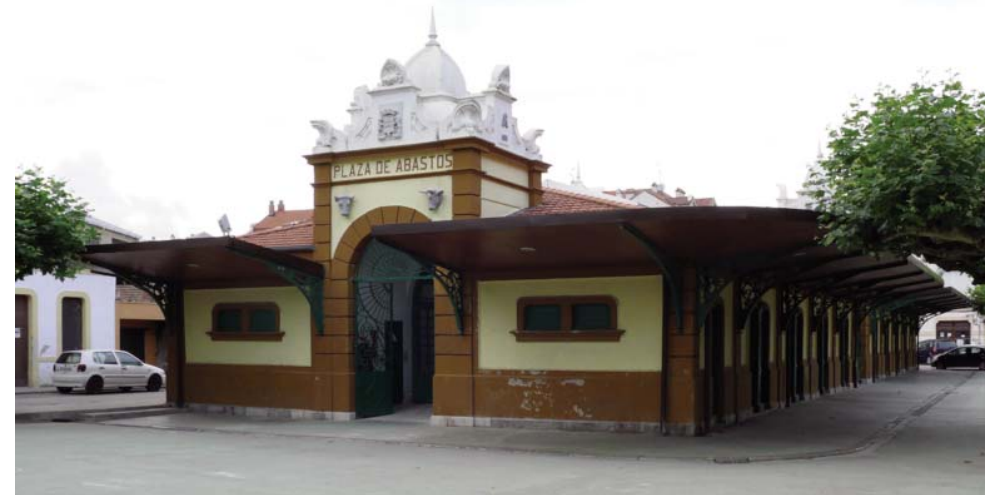

Somos conscientes que una vez cesa la actividad de una fábrica se pierden habitualmente dos de los tres fundamentos que la sustentaron. Los primeros en desaparecer son obviamente los obreros. En segundo lugar, a veces simultáneamente, la maquinaria es vendida por los propietarios, generalmente como chatarra, aunque no hay que descartar que pueda continuar su vida útil en otro establecimiento. Sin obreros y sin maquinaria sólo nos queda la arquitectura, la mayor parte de las veces reducida a las paredes de un edificio que en el pasado fue productivo.

Pero, aunque la historia haya querido que tan sólo quede el contenedor de estas fábricas, es nuestro deber reivindicarlo como elemento icónico de nuestra historia, de la memoria del trabajo, porque no debemos olvidar que en el interior de esas paredes hoy descarnadas, bajo esas cubiertas desvencijadas trabajaron cientos o miles de obreros.

Esperamos que este repaso somero al patrimonio industrial agroalimentario de Cantabria sirva para abrir una ventana hacia ese pasado, pero sobre todo para que la ciudadanía empiece a mirar con unos ojos diferentes, más complacientes, lo que se encuentra a su alrededor y que no menosprecie esos talleres, naves... que se encuentran próximos y que piense que allí donde hubo, por ejemplo, una chimenea, hubo un establecimiento industrial que merece su atención porque forma parte de su propia historia.

\section{Bibliografia}

Ansola Fernández, Alberto. 1999. De las escabecherias a las semiconservas: antecedentes, irrupción y desarrollo de la industria conservera de pescado en Cantabria. Publicaciones del Instituto de Etnografia y Folklore Hoyos Sáinz, 14: 297-343.

Ansola Fernández, Alberto y Sierra Álvarez, José. 2007. Caminos y fábricas de harina en el corredor del Besaya. Historia, geografia y patrimonio. Santander: Consejería de Medio Ambiente de Cantabria/CIMA.

Casado Cimiano, Pedro. 2000. Siglo y medio de historia de la industria lechera de Cantabria. Torrelavega: Ed. Besaya.

Casado Cimiano, Pedro, Aguayo Herrera, Francisco Jesús y Sainz García, Francisco. 2005. La coo perativa lechera SAM Imágenes para recordar. Santander: Ed. Cantabria Tradicional.

Comin Comin, Francisco y Martín Aceña, Pablo. 1999. Tabacalera y el estanco de tabaco en España (1636-1998), Madrid: Fundación Tabacalera.

Cueto Alonso, Gerardo J. 2009. El proyecto inconcluso de la fábrica de productos dietéticos de Max F. Berlowitz en Entrambasaguas (Cantabria). En Patrimonio industrial agroalimentario. Testimonios cotidianos del diálogo intercultural. Gijón: INCUNA, Asociación de Arqueología Industrial. 497-506.

Cueto Alonso, Gerardo J. 2010. El paisaje mineroindustrial de Torrelavega (Cantabria) y su 
comarca. En Actas del V Congreso Conservación del Patrimonio Industrial y de la Obra Pública en España. Gijón: TICCIH-España. 373-380.

Cueto Alonso, Gerardo J. 2011. La Lechera Montañesa. En Biel Ibáñez, M. P. y Cueto Alonso, G. J. (Coord.): 100 elementos del Patrimonio Industrial en España. Zaragoza: TICCIH-España, Instituto del Patrimonio Cultural de España. 152-153.

Cueto Alonso, Gerardo J. 2014. El papel del patrimonio industrial en la remodelación de la fachada maritima de Santander. En Patrimonio maritimo, fluvial y pesquero. Identidad, transporte, turismo, paisajes y sostenibilidad. Gijón: INCUNA, Asociación de Arqueología Industrial. 291-296.

De la Puente Fernández, Leonor. 1992. Transformaciones agrarias en Cantabria. 1860-1930. Especialización vacuna y construcción del espacio agrario. Santander: Universidad de Cantabria

Escudero Domínguez, Luis Javier. 2007. Acciughe salate alla vera carne: historia de los salazoneros italianos en Cantabria. Santander: Servicio de Publicaciones de la Universidad de Cantabria.

García Barber, Xavier. 2015. La industria cervecera santanderina a la sombra del mercado de Indias. Scripta Nova. Revista Electrónica de Geografia y Ciencias Sociales. 518. http://www.ub.es/geocrit/sn/sn-518.pdf.

Hoyo Aparicio, Andrés. 1993. Todo mudó de repente. El horizonte mercantil de la burguesía mercantil en Santander, 1820-1874. Santander: Universidad de Cantabria.

Ortega Valcárcel, José. 1986. Cantabria 1886-1986. Formación y desarrollo de una economía moder na. Santander: Cámara de Comercio Industria y Navegación.

Ortega Valcárcel, José. 1996. Gentes del mar en Can tabria. Santander: Universidad de Cantabria

Palacio Atard, Vicente. 1960 El comercio de Castilla y el puerto de Santander en el siglo XVIII: notas para su estudio. Madrid: Consejo Superior de Investigaciones Científicas.

Ruiz Gómez, Fernando. 2011. Una industria en ruinas: arqueologia industrial en Campoo. Cuadernos de Campoo, 10: 5-32.

Sazatornil Ruiz, Luis. 1996. Arquitectura y desarrollo urbano de Cantabria en el siglo XIX. Santander: Universidad de Cantabria.

Sierra Álvarez, José. 1998. Las marcas del trabajo: el patrimonio industrial inmuebles de la Cantabria del siglo XX. En: El siglo de los cambios. Cantabria 1898-1998. Santander: Caja Cantabria. 290-327.

Sierra Álvarez, José y Corbera Millán, Manuel. 2007. Chimeneas en la aldea: las transformaciones inducidas por la instalación de Nestlé en La Penilla de Cayón (Cantabria), 1902-1935. Scripta Nova. Revista electrónica de geografia y ciencias sociales. 231. http://www.ub.es/geocrit/sn/sn-231.htm

Fecha final recepción artículos: 24/04/2016

Fecha aceptación:

$19 / 06 / 2016$

Articulo sometido a revisión por dos revisores independientes por el método doble ciego. 